\title{
A MACROECONOMIA DAS EPIDEMIAS: HETEROGENEIDADE INTERESTADUAL NO BRASIL
}

\author{
Luan Borelli \\ Geraldo Sandoval Góes
}
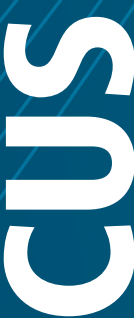

$\boldsymbol{n}$

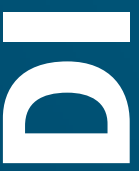

$\frac{1}{2}$
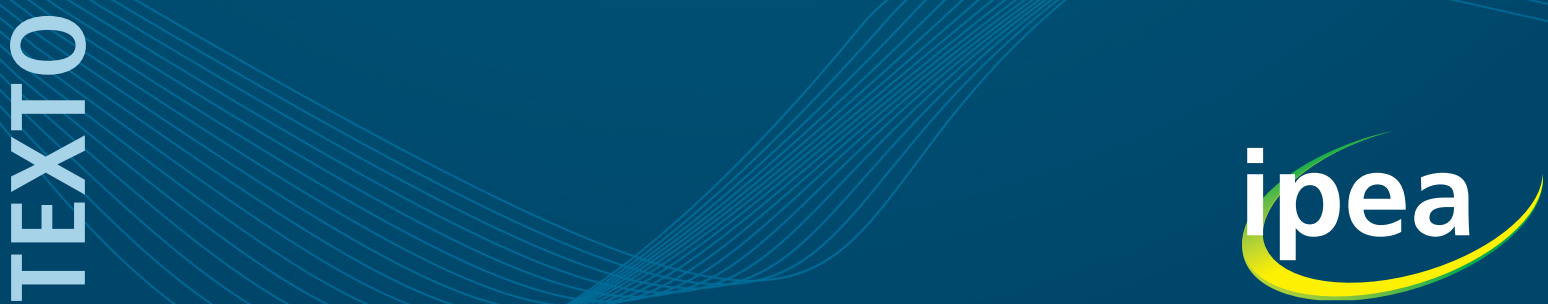



\section{TEXTO PARA DISCUSSÃO}

Brasília, agosto de 2020

A MACROECONOMIA DAS EPIDEMIIAS:

HETEROGENEIDADE INTERESTADUAL NO BRASIL

Luan Borelli ${ }^{1}$

Geraldo Sandoval Góes²

1. Assistente de pesquisa na Diretoria de Estudos e Políticas Macroeconômicas (Dimac) do Ipea.

2. Especialista em políticas públicas e gestão governamental na Dimac do Ipea. 


\section{Governo Federal \\ Ministério da Economia \\ Ministro Paulo Guedes}

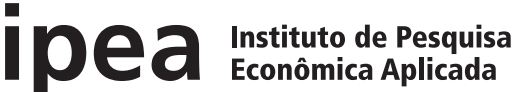

Fundação pública vinculada ao Ministério da Economia, o Ipea fornece suporte técnico e institucional às ações governamentais - possibilitando a formulação de inúmeras políticas públicas e programas de desenvolvimento brasileiros - e disponibiliza, para a sociedade, pesquisas e estudos realizados por seus técnicos.

\section{Presidente}

Carlos von Doellinger

Diretor de Desenvolvimento Institucional

Manoel Rodrigues Junior

Diretora de Estudos e Políticas do Estado, das Instituições e da Democracia

Flávia de Holanda Schmidt

\section{Diretor de Estudos e Políticas}

Macroeconômicas

José Ronaldo de Castro Souza Júnior

Diretor de Estudos e Políticas Regionais, Urbanas e Ambientais

Nilo Luiz Saccaro Júnior

Diretor de Estudos e Políticas Setoriais de Inovação e Infraestrutura

André Tortato Rauen

Diretora de Estudos e Políticas Sociais

Lenita Maria Turchi

Diretor de Estudos e Relações Econômicas

e Políticas Internacionais

Ivan Tiago Machado Oliveira

\footnotetext{
Assessora-chefe de Imprensa

e Comunicação

Mylena Fiori

Ouvidoria: http://www.ipea.gov.br/ouvidoria

URL: http://www.ipea.gov.br
}

\section{Texto para Discussão}

Publicação seriada que divulga resultados de estudos e pesquisas em desenvolvimento pelo Ipea com o objetivo de fomentar o debate e oferecer subsídios à formulação e avaliação de políticas públicas.

(C) Instituto de Pesquisa Econômica Aplicada - ipea 2020

Texto para discussão / Instituto de Pesquisa Econômica Aplicada.- Brasília : Rio de Janeiro : Ipea, 1990-

ISSN 1415-4765

1.Brasil. 2.Aspectos Econômicos. 3.Aspectos Sociais. I. Instituto de Pesquisa Econômica Aplicada.

CDD 330.908

As publicações do Ipea estão disponíveis para download gratuito nos formatos PDF (todas) e EPUB (livros e periódicos). Acesse: http://www.ipea.gov.br/portal/publicacoes

As opiniões emitidas nesta publicação são de exclusiva e inteira responsabilidade dos autores, não exprimindo, necessariamente, o ponto de vista do Instituto de Pesquisa Econômica Aplicada ou do Ministério da Economia.

É permitida a reprodução deste texto e dos dados nele contidos, desde que citada a fonte. Reproduções para fins comerciais são proibidas.

JEL: E1, I1, H0. 


\section{SUMÁRIO}

RESUMO

1 INTRODUÇÃO

.7

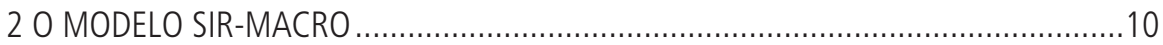

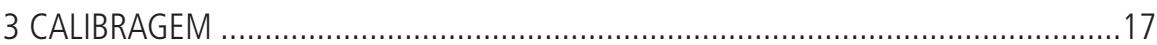

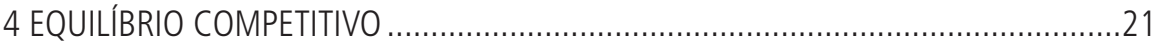

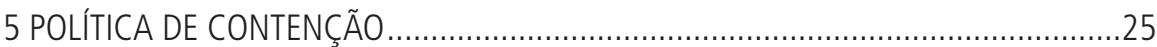

6 AS CONSEQUÊNCIAS DA POLÍTICA ÓTIMA DE CONTENÇÃO ..............................29

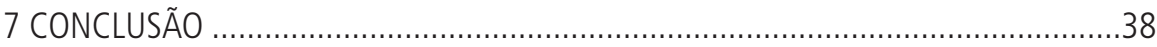

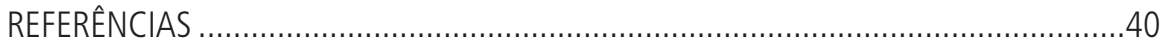

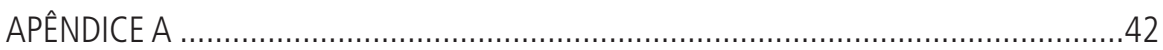

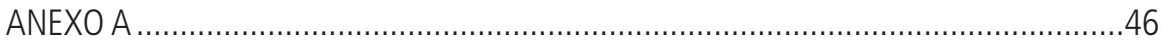





\section{RESUMO}

Neste trabalho utilizamos o modelo SIR-macro de Eichenbaum et al. (2020), em sua versão completa, para efetuar um estudo comparativo das interaçóes entre as decisóes econômicas e a pandemia da Covid-19 nos estados de São Paulo, Amazonas, Ceará, Rio de Janeiro e Pernambuco, que, no momento da pesquisa, apresentavam as situaçóes mais críticas entre os 26 estados brasileiros. Com o objetivo de analisar qualitativamente como as principais diferenças intrínsecas a cada estado podem afetar as suas dinâmicas epidêmicas e seus resultados, computamos, para os cinco estados, os resultados do modelo no equilíbrio competitivo e na presença da adoção de políticas ótimas de contenção e avaliamos as consequências destas políticas. Concluímos que as características intrínsecas dos cinco diferentes estados implicam diferenças relevantes na dinâmica epidêmica, nas políticas ótimas de contenção, no efeito da adoção destas políticas e na severidade das recessões econômicas.

Palavras-chave: epidemia, Covid-19, estados, recessões, políticas de contenção, modelo SIR-macro. 



\section{INTRODUÇÃO}

Conforme o vírus da Covid-19 se espalha pelo território brasileiro, governadores de todo o país enfrentam o desafio de entender e gerenciar a epidemia que assola os estados que comandam. Quando comparado a outros países, este desafio se demonstra ainda maior no Brasil, dada a dimensão continental deste país e a heterogeneidade das características de seus diversos estados. Um recente estudo de Hallal et al. (2020) ilustra como essa heterogeneidade pode afetar as dinâmicas epidêmicas em todo o país. $\mathrm{O}$ estudo reporta a primeira onda de pesquisas de seroprevalência com amostras probabilísticas domésticas de 133 grandes cidades sentinelas do Brasil, incluindo 25.025 participantes de todos os 26 estados e do Distrito Federal, e encontra que a seroprevalência de anticorpos para Sars-COV-2, avaliada usando um teste rápido de fluxo lateral, variou acentuadamente nas cidades e regiốes, de menos de $1 \%$ na maioria das cidades das regióes Sul e Centro-Oeste a até $25 \%$ na cidade de Breves, na região amazônica (Norte).

Neste trabalho, nosso objetivo é investigar como e o quanto as diferenças interestaduais afetam as dinâmicas epidêmicas dos estados brasileiros. A resposta a essa questão pode prover intuiçôes a respeito das consequências da condução de políticas de contenção no âmbito agregado (federal) ou desagregado (estadual).

Para efetuar esta análise utilizamos o simples arcabouço do modelo SIR-macro, proposto por Eichenbaum et al. (2020). Diferente dos modelos epidemiológicos que têm sido amplamente utilizados em tentativas de prever o curso das epidemias - Ferguson et al. (2020), por exemplo -, o modelo SIR-macro estende o modelo clássico SIR (acrônimo para suscetíveis, infectados e recuperados) proposto originalmente por Kermack e McKendrick (1927), incorporando um importante fator com o potencial de afetar significativamente a dinâmica das epidemias: a interação entre as decisôes econômicas e as taxas de infecção. Neste novo modelo estendido, as decisôes dos agentes em abrir mão de consumo e de horas de trabalho reduzem, por um lado, a severidade da epidemia (medida em número total de mortes), mas agravam, por outro lado, o tamanho da recessão econômica dela resultante.

Essa extensão não apenas contribui para resultados mais precisos da evolução da epidemia, como também permite a análise dos seus efeitos sobre agregados macroeconômicos. No modelo SIR-macro, a ocorrência de uma epidemia tem efeito tanto sobre 
a demanda quanto sobre a oferta agregada da economia. O efeito sobre a oferta dá-se pois, como a epidemia expõe os trabalhadores ao vírus em seus ambientes de trabalho, estes reagem ao risco de serem contaminados reduzindo horas de trabalho ofertadas. Analogamente, o efeito sobre a demanda ocorre pois, como a epidemia expóe os consumidores ao vírus nos ambientes de consumo, estes reagem ao risco de serem contaminados reduzindo suas atividades de consumo. Os efeitos sobre a oferta e a demanda agregada atuam conjuntamente, gerando uma grande e persistente recessáo.

Uma importante característica deste modelo é que o seu equilíbrio competitivo não é socialmente ótimo. A população infectada pelo vírus não internaliza por completo o efeito de suas decisóes de consumo e trabalho na disseminação do vírus. Para lidar com estas externalidades infecciosas, os governadores podem adotar políticas de contenção que reduzam o consumo e as horas trabalhadas pelos agentes. Reduzindo as interaçôes econômicas dos agentes, essas políticas de contenção, por um lado, exacerbam as recessões, mas, por outro lado, reduzem a quantidade de mortes resultante da epidemia.

Neste trabalho computamos o modelo SIR-macro para cinco estados brasileiros. Consideramos, para cada estado, dois cenários: um sob o equilíbrio competitivo e outro sob a adoção de políticas ótimas de contenção. O critério de seleção dos cinco estados foi a criticidade de suas situaçóes epidêmicas no momento da pesquisa. Assim, selecionamos os cinco estados que apresentavam a situação epidêmica mais crítica, até o momento da pesquisa, em termos de número de casos notificados acumulados. Os estados selecionados foram São Paulo, Amazonas, Ceará, Rio de Janeiro e Pernambuco.

As diferentes características particulares destes estados foram incorporadas por meio de nossa estratégia de calibragem para os valores dos parâmetros e variáveis do modelo. Nossa calibragem permite que os resultados incorporem diferenças interestaduais relativas às seguintes características: $i$ ) tamanho da população; ii) renda per capita; iii) tempo médio dedicado ao trabalho; iv) tempo médio no transporte; $v$ ) tempo médio dedicado a afazeres domésticos; vi) quantidade média de pessoas por residência; vii) quantidade de pessoas ocupadas na força de trabalho, viii) quantidade de estudantes; e $i x$ ) taxas de fatalidade estimadas com a evolução da epidemia até o momento da pesquisa. 
Ao computar as dinâmicas epidêmicas para diferentes estados, torna-se possível efetuar análises comparativas das epidemias não apenas dentro dos próprios estados, comparando o cenário de equilíbrio competitivo com o cenário de adoção de políticas ótimas de contenção, como também entre os cinco diferentes estados. Essas comparaçôes interestaduais permitem verificar como as diferçentes características destes estados influenciam os diversos resultados do modelo.

Comparamos as diferenças das dinâmicas epidêmicas e de suas consequências entre estes diferentes estados tanto para o cenário de equilíbrio competitivo (sem adoção de políticas de contenção) quanto para o cenário em que são adotadas políticas ótimas de contenção. Também comparamos as diferenças das políticas ótimas de contenção requeridas para cada estado e avaliamos os efeitos da adoção destas políticas sobre cada um destes estados, tanto isoladamente quanto em comparaçáo aos demais.

Como resultado destas análises, concluímos que as características particulares dos cinco diferentes estados implicam diferenças relevantes em suas dinâmicas epidêmicas, nas políticas ótimas de contenção a serem adotadas, no efeito da adoção destas políticas e na severidade das recessóes econômicas resultantes da pandemia. Esta conclusão corrobora com ênfase que vem sido dada na literatura nacional à importância da análise desagregada do país para a formulaçáo de políticas de combate à pandemia, podendo a adoção de uma política única para um país das dimensôes do Brasil provocar reaçóes desproporcionais nas esferas estaduais. Com efeito, se a política do país for acima da requerida para determinados estados em particular, estes podem sofrer agravos desnecessários de suas recessóes econômicas. Num pior cenário, por outro lado, se a política adotada por todo o país for abaixo da requerida por determinados estados, a consequência pode ser a elevação do número de mortos em decorrência da pandemia nesses estados. Portanto, em última análise, concluímos que o enfrentamento desagregado da pandemia pode colaborar tanto para a menor severidade da recessão econômica sofrida pelo país como um todo, quanto para a preservação de um maior número de vidas.

O presente trabalho está estruturado da seguinte forma. Na seção 2 é apresentado o modelo SIR-macro em sua versão completa. A exposição do modelo é adaptada de Eichenbaum et al. (2020). Na seção 3 apresentamos nossa estratégia de calibragem para o modelo e os valores utilizados para os seus parâmetros e variáveis para cada estado. $\mathrm{Na}$ seção 4 apresentamos e descrevemos os resultados do modelo para os cinco estados no equilíbrio 
competitivo. Na seção 5 incluímos políticas de contenção, computamos as políticas ótimas de contenção para cada um dos cinco estados, as descrevemos e apresentamos os resultados do modelo para o cenário em que os cinco estados adotam estas políticas ótimas de contenção. Na seção 6 comparamos os resultados em que a as políticas ótimas de contenção são adotadas com os resultados de equilíbrio competitivo e apuramos as consequências destas políticas de contenção. Na seção 7 conclui-se o trabalho.

\section{MODELO SIR-MACRO}

Nas seçôes subsequentes descrevemos, com algumas adaptações, a versão completa do modelo SIR-macro conforme exposta em Eichenbaum et al. (2020). As adaptaçóes foram necessárias pois em Eichenbaum et al. (2020) a versão completa do modelo é construída, ao longo das seçôes do artigo, com a inclusão gradativa de extensóes ao modelo SIR-macro básico. Como, neste texto para discussão, ara apresentá-lo em uma única seção. A versão completa do modelo contempla três principais características: a taxa de mortalidade endógena como função da população infectada, a possibilidade do descobrimento de tratamentos efetivos que curem a população infectada e a possibilidade do descobrimento de vacinas.

\subsection{0 arcabouço econômico e a economia pré-infecção}

A populaçáo da economia é representada por um continuum de agentes de medida igual a um que, ex-ante, são idênticos. Estes agentes maximizam a função objetivo

$$
U=\sum_{t=0}^{\infty} \beta_{t} u\left(c_{t}, n_{t}\right)
$$

onde $\beta \in(0,1)$ denota o fator de desconto intertemporal e $c_{t}$ e $n_{t}$ denotam o consumo e as horas trabalhadas, respectivamente. Por simplicidade, assume-se a forma funcional da utilidade como

$$
u\left(c_{t}, n_{t}\right)=\ln c_{t}-\frac{\theta}{2} n_{t}^{2}
$$


A restrição orçamentária do agente representativo é

$$
\left(1+\mu_{t}\right) c_{t}=w_{t} n_{t}+\Gamma_{t}
$$

onde $w_{t}$ denota o salário real, $\mu_{t}$ a taxação sobre o consumo e $\Gamma_{t}$ as transferências lump sum recebidas do governo. Assim como em Eichenbaum et al. (2020), $\mu_{t}$ é entendido como uma proxy para as medidas de contenção conduzidas com o objetivo de reduzir interaçôes sociais. Por esta razão, doravante referir-se-á a este parâmetro como taxa de contenção.

A condição de primeira ordem para o problema do agente representativo é

$$
\left(1+\mu_{t}\right) \theta n_{t}=c_{t}^{-1} w_{t}
$$

No modelo, há ainda um continuum de firmas representativas de medida unitária que atuam competitivamente produzindo bens de consumo $\left(C_{t}\right)$ e usando horas de trabalho $\left(N_{t}\right)$ impulsionadas por tecnologia:

$$
C_{t}=A N_{t}
$$

As firmas representativas escolhem o quanto de horas de trabalho utilizar de modo a maximizar os seus lucros no tempo $t, \Pi_{t}$ :

$$
\Pi_{t}=A N_{t}-w_{t} N_{t}
$$

A restrição orçamentária do governo é:

$$
\mu_{t} c_{t}=\Gamma_{t}
$$

No equilíbrio, $n_{t}=N_{t}$ e $c_{t}=C_{t}$.

\subsection{0 arcabouço epidemiológico e o início da epidemia}

A população é dividida em quatro grupos: suscetíveis, infectados, recuperados e falecidos. As pessoas que ainda não foram expostas à doença são classificadas como suscetíveis. As pessoas que já contraíram a doença são classificadas como infectadas. 
Finalmente, as pessoas que sucumbem à doença são classificadas como falecidas. As frações da população em cada um destes quatro grupos, no tempo $t$, são denotadas por $S_{t}, I_{t}, R_{t}$ e $D_{t}$, respectivamente. O número de novos infectados em $t$ é denotado por $T_{t}$.

Indivíduos suscetíveis podem ser infectados de três maneiras: i) enquanto consomem; ii) enquanto trabalham; ou iii) de outras formas não relacionadas diretamente ao consumo e ao trabalho, como em transporte, em encontros sociais, em casa ou simplesmente pelo contato com superfícies contaminadas.

O número de novos infectados que resulta das atividades de consumo é dado por $\pi_{1}\left(S_{t} C_{t}^{s}\right)\left(I_{t} C_{t}^{i}\right)$. Os termos $S_{t} C_{t}^{s}$ e $I_{t} C_{t}^{i}$ representam os gastos totais de consumo dos indivíduos suscetíveis e infectados, respectivamente. $\mathrm{O}$ parâmetro $\pi_{1}$ reflete tanto a quantidade de tempo utilizada fazendo compras quanto a probabilidade de infecção resultante da atividade de consumo.

O número de novos infectados que resulta das atividades de trabalho é dado por $\pi_{2}\left(S_{t} N_{t}^{s}\right)\left(I_{t} N_{t}^{i}\right)$. Os termos $S_{t} N_{t}^{s}$ e $I_{t} N_{t}^{i}$ representam o total de horas trabalhadas pelos indivíduos suscetíveis e infectados, respectivamente. $\mathrm{O}$ parâmetro $\pi_{2}$ reflete a probabilidade de infecção resultante das atividades de trabalho.

O número de outros tipos de encontros, não relacionados a consumo e trabalho, entre suscetíveis e infectados é $S_{t} I_{t}$. O número de novos infectados resultante destes encontros é dado por $\pi_{3} S_{t} I_{t}$. O parâmetro $\pi_{3}$ reflete a probabilidade de infecção resultante das atividades não relacionadas ao consumo ou ao trabalho.

O número total de novos infectados é então dado por:

$$
T_{t}=\pi_{1}\left(S_{t} C_{t}^{s}\right)\left(I_{t} C_{t}^{i}\right)+\pi_{2}\left(S_{t} N_{t}^{S}\right)\left(I_{t} N_{t}^{i}\right)+\pi_{3} S_{t} I_{t}
$$

É interessante notar que o modelo SIR canônico de Kermack e McKendrick (1927) é um caso especial do modelo SIR-macro, no qual a propagação da doença não é relacionada com a atividade econômica. Este caso é caracterizado pelos valores paramétricos $\pi_{1}=\pi_{2}=0$. 
$\mathrm{O}$ número de infectados em $t+1$ é igual ao número de indivíduos infectados em $t\left(I_{t}\right)$ mais o número de novos infectados $\left(T_{t}\right)$ menos o número de infectados que se recuperaram $\left(\pi_{r} I_{t}\right)$, e o número de infectados que morreram $\pi_{d} I_{t}$ :

$$
I_{t+1}=I_{t}+T_{t}-\left(\pi_{r}+\pi_{d}\right) I_{t}
$$

onde $\pi_{r}$ é a taxa de indivíduos recuperados da infecção e $\pi_{d}$ é a taxa de mortalidade, ou seja, a probabilidade de um infectado morrer. Para incorporar o efeito da reduçáo gradual da capacidade do sistema de saúde sobre a taxa de mortalidade, essa probabilidade é modelada como uma função convexa de uma fração $\kappa$ da população infectada:

$$
\pi_{d t}=\pi_{d}+\kappa I_{t}^{2}
$$

A convenção temporal da equação (9) é a seguinte: interaçôes sociais acontecem no início do período, momento em que indivíduos suscetíveis e infectados se encontram. Então, mudanças no estado de saúde não relacionados com as interaçôes sociais (recuperaçôes e mortes) ocorrem. No fim do período, finalmente, as consequências das interaçôes sociais se materializam e $T_{t}$ indivíduos suscetíveis passam a ser classificados como infectados.

O número de recuperados em $t+1$ é o número de recuperados em $t\left(R_{t}\right)$ mais o número de infectados que acabaram de se recuperar $\pi_{r} I_{t}$ :

$$
R_{t+1}=R_{t}+\pi_{r} I_{t}
$$

Finalmente, o número de falecidos em $t+1$ é o número de falecidos em $t\left(D_{t}\right)$ mais o número de novas mortes $\pi_{d} I_{t}$ :

$$
D_{t+1}=D_{t}+\pi_{d} I_{t}
$$

A população total evolui de acordo com a lei de movimento

$$
P O P_{t+1}=P O P_{t}-\pi_{d} I_{t}
$$

$\operatorname{com} P O P_{0}=1$. 
Assume-se que, no tempo zero, uma fração $\varepsilon$ de pessoas suscetíveis é infectada pelo vírus por meio de exposições zoonóticas, isto é, o vírus é inicialmente transmitido diretamente de animais para humanos:

$$
\begin{aligned}
& I_{0}=\varepsilon \\
& S_{0}=1-\varepsilon .
\end{aligned}
$$

Assume-se também que toda a população está ciente do número inicial de infectados e entende as leis de movimento que governam as dinâmicas da saúde. Isso significa que a população toma como dados agregados como $I_{t} C_{t}^{i}$ e $I_{t} N_{t}^{i}$.

Descreveremos agora o problema de otimização dos diferentes tipos de indivíduos da economia. A variável $U_{t}^{j}$ denota a utilidade no tempo $t$ de um agente do tipo $j(j=s, i, r)$. A restrição orçamentária de um indivíduo do tipo $j$ é

$$
\left(1+\mu_{t}\right) c_{t}^{j}=w_{t} \phi^{j} n_{t}^{j}+\Gamma_{t}
$$

onde $c_{j}$ e $n_{t}^{j}$ denotam o consumo e as horas trabalhadas do agente de tipo $j$, respectivamente. $\mathrm{O}$ parâmetro que governa a produtividade do trabalho, $\phi^{j}$, é igual a um para indivíduos suscetíveis e recuperados $\left(\phi^{S}=\phi^{r}=1\right)$ e menor que um para indivíduos infectados $\left(\phi^{i}<1\right)$.

\subsubsection{Suscetíveis}

A utilidade dos indivíduos suscetíveis, $U_{t}^{s}$, é

$$
U_{t}^{s}=u\left(c_{t}^{s}, n_{t}^{s}\right)+\left(1-\delta_{v}\right)\left[\left(1-\tau_{t}\right) \beta U_{t+1}^{s}+\tau_{t} \beta U_{t+1}^{i}\right]+\delta_{v} \beta U_{t+1}^{r}
$$

Os indivíduos suscetíveis têm consciência de que consumindo e trabalhando menos podem reduzir a probabilidade de serem infectados. A variável $\tau_{t}$ representa a probabilidade de um indivíduo suscetível ser infectado:

$$
\tau_{t}=\pi_{1} c_{t}^{S}\left(I_{t} C_{t}^{i}\right)+\pi_{2} n_{t}^{s}\left(I_{t} N_{t}^{i}\right)+\pi_{3} I_{t}
$$


O parâmetro $\delta_{v}$ representa a probabilidade, por período, de uma vacina ser descoberta. Com probabilidade $1-\delta_{v}$ um indivíduo suscetível em $t$ continua suscetível em $t+1$. Com probabilidade $\delta_{v}$ esse indivíduo é vacinado e se torna imune à doença. Assim, no período $t+1$, a situação de saúde desse indivíduo torna-se idêntica à de um indivíduo recuperado. A vacina não tem impacto sobre indivíduos que estavam infectados ou foram recuperados.

As condições de primeira ordem para o consumo e as horas trabalhadas são:

$$
\begin{aligned}
& u_{1}\left(c_{t}^{s}, n_{t}^{s}\right)-\left(1+\mu_{t}\right) \lambda_{b t}^{s}+\lambda_{\tau t} \pi_{1}\left(I_{t} C_{t}^{I}\right)=0 \\
& u_{2}\left(c_{t}^{s}, n_{t}^{s}\right)+w_{t} \lambda_{b t}^{s}+\lambda_{\tau t} \pi_{2}\left(I_{t} N_{t}^{I}\right)=0
\end{aligned}
$$

$\lambda_{b t}^{S}$ e $\lambda_{\tau t}$ são os multiplicadores de Lagrange associados às restriçóes (16) e (18), respectivamente. A condição de primeira ordem de $\tau_{t}$ é:

$$
\beta\left(U_{t+1}^{i}-U_{t+1}^{S}\right)-\lambda_{\tau t}=0
$$

\subsubsection{Infectados}

A utilidade dos indivíduos infectados, $U_{t}^{i}$, é

$$
U_{t}^{i}=u\left(c_{t}^{i}, n_{t}^{i}\right)+\left(1-\delta_{c}\right)\left[\left(1-\pi_{r}-\pi_{d}\right) \beta U_{t+1}^{i}+\pi_{r} \beta U_{t+1}^{r}\right]+\beta \delta_{c} U_{t+1}^{r} .
$$

A expressão acima para $U_{t}^{i}$ incorpora a hipótese comum em modelos macroeconômicos relacionados à saúde de que o custo da morte é a renúncia da utilidade da vida.

O parâmetro $\delta_{c}$ representa a probabilidade, por período, de um tratamento efetivo que cura indivíduos infectados ser descoberto. Quando um tratamento como este é descoberto, ele é aplicado à toda a população infectada no período da descoberta e nos períodos subsequentes, transformando todos os indivíduos infectados em recuperados. Como resultado, o número de novas mortes passa a ser zero. 
As condiçôes de primeira ordem para o consumo e as horas trabalhadas são:

$$
\begin{aligned}
& u_{1}\left(c_{t}^{i}, n_{t}^{i}\right)=\lambda_{b t}^{i}\left(1+\mu_{t}\right), \\
& u_{2}\left(c_{t}^{i}, n_{t}^{i}\right)=-\phi^{i} w_{t} \lambda_{b t}^{i}
\end{aligned}
$$

onde $\lambda_{b t}^{i}$ é o multiplicador de Lagrange associado à restrição (16).

\subsubsection{Recuperados}

A utilidade dos indivíduos recuperados, $U_{t}^{r}$, é

$$
U_{t}^{r}=u\left(c_{t}^{r}, n_{t}^{r}\right)+\beta U_{t+1}^{r}
$$

As condições de primeira ordem para o consumo e as horas trabalhadas são:

$$
\begin{aligned}
& u_{1}\left(c_{t}^{r}, n_{t}^{r}\right)=\lambda_{b t}^{r}\left(1+\mu_{t}\right), \\
& u_{2}\left(c_{t}^{r}, n_{t}^{r}\right)=-w_{t} \lambda_{b t}^{r}
\end{aligned}
$$

onde $\lambda_{b t}^{r}$ é o multiplicador de Lagrange associado à restrição (16).

\subsubsection{Restrição orçamentária do governo}

A restrição orçamentária do governo é

$$
\mu_{t}\left(S_{t} c_{t}^{S}+I_{t} c_{t}^{i}+R_{t} c_{t}^{r}\right)=\Gamma_{t}\left(S_{t}+I_{t}+R_{t}\right)
$$

\subsubsection{Equilíbrio}

Em equilíbrio, cada indivíduo resolve seu problema de maximização e a restrição orçamentária do governo é satisfeita. Ademais, os mercados de bens e de trabalho se equilibram:

$$
S_{t} C_{t}^{S}+I_{t} C_{t}^{i}+R_{t} C_{t}^{r}=A N_{t}
$$




$$
S_{t} N_{t}^{s}+I_{t} N_{t}^{i} \phi^{i}+R_{t} N_{t}^{r}=N_{t}
$$

No anexo A é descrito o algoritmo proposto por Eichenbaum et al. (2020) para computar o equilíbrio.

\section{CALIBRAGEM}

Nesta seçáo apresentamos nossa estratégia de calibragem utilizada para a determinaçáo dos parâmetros do modelo para os cinco estados escolhidos, a saber, São Paulo, Amazonas, Ceará, Rio de Janeiro e Pernambuco, os quais no momento da pesquisa apresentavam as situaçôes mais críticas entre os 26 estados brasileiros.

Uma primeira observação que deve ser feita trata da convenção de tempo utilizada para os exercícios. Como o principal objetivo do modelo não é computar previsóes quantitativas pontuais a respeito de questôes como a data do pico de infectados, decidimos por abrir mão da definiçáo de uma periodicidade específica para o tempo do modelo. Em vez disso, optamos por normalizar a duração total do intervalo de tempo para o qual os exercícios foram computados para 1. Assim, a interpretação do tempo do modelo passa a ser em relação ao progresso (\%) da duração total da epidemia, a qual só se terá conhecimento ex-post. Assim, eximimos este trabalho de quaisquer responsabilidades preditivas que a ele pudessem ser atribuídas e enfatizamos a natureza qualitativa e comparativa de seus resultados.

Para calibrar o valor de $\kappa$ para cada estado utilizamos as estimativas de taxas de fatalidade entre infectados (IFR - infection fatality rate, em inglês) estimadas por Mellan et al. (2020), no Report 21 da Imperial College, para uma série de estados brasileiros. Calibramos o valor de $\kappa$ para cada um dos cinco estados de modo que os picos das taxas de mortalidade no equilíbrio competitivo adequem-se às taxas de fatalidade entre infectados estimadas pelo Imperial College. Apesar da taxa de mortalidade ser endógena ao modelo, ela ainda necessita de um valor inicial. Seguindo Rabelo e Soares (2020), determinamos este valor como sendo 0,3\% para todos os estados, valor obtido ponderando a taxa de mortalidade verificada na Coreia do Sul país que efetuou o maior volume de testagens per capita até então - pela pirâmide etária brasileira pré-epidêmica. 
Procedendo para a nossa estratégia de calibragem para os valores de $\pi_{1}, \pi_{2}$ e $\pi_{3}$ para cada estado, iniciamos, assim como é comum em estudos epidemiológicos, por adotar a premissa utilizada em Eichenbaum et al. (2020) de que a importância relativa de diferentes modos de transmissão é semelhante entre diferentes doenças respiratórias. Ferguson et al. (2006) argumentam que, no caso da influenza, 30\% das transmissôes ocorreram em casa, 33\% ocorreram em atividades comunitárias gerais e 37\% ocorreram em escolas e locais de trabalho. Com base na premissa adotada, utilizamos essas porcentagens como base para a nossa calibragem.

Assim como em Eichenbaum et al. (2020) calibramos os valores de $\pi_{1}, \pi_{2}$ e $\pi_{3}$ de modo a satisfazerem o sistema

$$
\begin{aligned}
& \frac{\pi_{1} C^{2}}{\pi_{1} C^{2}+\pi_{2} N^{2}+\pi_{3}}=\alpha_{1} \\
& \frac{\pi_{2} N^{2}}{\pi_{1} C^{2}+\pi_{2} N^{2}+\pi_{3}}=\alpha_{2} \\
& \frac{\pi_{3}}{\pi_{1} C^{2}+\pi_{2} N^{2}+\pi_{3}}=\alpha_{3}
\end{aligned}
$$

onde $C$ e $N$ são o consumo e as horas trabalhadas no estado estacionário pré-infecção. Note que $\alpha_{1}, \alpha_{2}$ e $\alpha_{3}$ são as parcelas das transmissóes que ocorrem no consumo, no trabalho e em outras atividades, respectivamente. Assim, o problema de calibragem de $\pi_{1}, \pi_{2}$ e $\pi_{3}$ é equivalente ao problema de calibragem de $\alpha_{1}, \alpha_{2}$ e $\alpha_{3}$ pois, uma vez calibradas estas parcelas, bastará resolver o sistema para que sejam obtidos os valores de $\pi_{1}$ , $\pi_{2}$ e $\pi_{3}$. Ainda, note que como $\alpha_{1}+\alpha_{2}+\alpha_{3}=1$, basta que duas das parcelas sejam calibradas para que a última seja obtida residualmente.

Por questôes de disponibilidade de dados, optamos por calibrar $\alpha_{2}$ e $\alpha_{3}$ e obter $\alpha_{1}$ residualmente. Calibramos a parcela das transmissóes que ocorrem no trabalho, $\alpha_{2}$, utilizando a mesma abordagem de Eichenbaum et al. (2020). Ponderamos as quantidades de estudantes e trabalhadores de cada estado em 10 e 4, respectivamente. Estes pesos dizem respeito à quantidade média de contatos físicos por dia na escola e no trabalho, obtidas no trabalho de Lee et al. (2010). Para a quantidade total de trabalhadores utilizou-se o número de pessoas de 14 anos ou mais de idade, na força de trabalho, ocupadas, por unidade da federação, obtidos no Sistema 
IBGE de Recuperação Automática (SIDRA), ${ }^{1}$ do Instituto Brasileiro de Geografia e Estatística (IBGE) e para a quantidade total de estudantes utilizou-se o número de estudantes de 4 anos ou mais de idade, por unidade de federação, obtidos também no SIDRA, ${ }^{2}$ do IBGE.

Calibramos a parcela das infecções que ocorre em outras atividades, $\alpha_{3}$, utilizando dados sobre: $i$ ) a proporçáo de horas diárias dedicadas aos cuidados de pessoas e/ ou afazeres domésticos das pessoas de 14 anos ou mais de idade; ii) o número médio de pessoas por domicílio; e iii) o tempo habitual de deslocamento para o trabalho dos indivíduos, conjuntamente a algumas hipóteses de calibragem. Tendo os valores de $\alpha_{2} \mathrm{e}$ $\alpha_{3}$ calibrados, obtemos residualmente o valor de $\alpha_{1}$ e, com estas três parcelas calibradas, finalmente resolvemos o sistema (31) para obter $\pi_{1}, \pi_{2}$ e $\pi_{3}$. Mais detalhes técnicos relativos à calibragem destes valores podem ser encontrados no apêndice $\mathrm{A}$.

A população inicial do modelo é normalizada para 1. Para cada estado, calibramos a populaçáo inicial de infectados $\varepsilon$ para representar um número inicial de 100 infectados em $\mathrm{t}=0$. Esta é, então, calculada como sendo:

$$
\varepsilon=\frac{100}{P O P}
$$

onde $P O P$ é a população residente estimada para o ano de 2019 para o estado em questáo, obtida pelo SIDRA ${ }^{3}$ do IBGE. Calibrando desta forma para cada estado foi possível captar e comparar o efeito dos diferentes tamanhos populacionais de cada estado sobre as dinâmicas locais da epidemia.

Assim como em Eichenbaum et al. (2020), calibramos os valores de A e $\theta$ de modo que, no estado estacionário pré-epidêmico, o agente representativo de cada estado trabalhe a média de horas trabalhadas da população de seu estado, e que receba a renda per capita da população de seu estado. Para isso, utilizamos a média de horas habitualmente trabalhadas por semana em todos trabalhos das pessoas de 14 anos ou mais de idade e o 
rendimento médio mensal real domiciliar per capita, a preços médios do ano, para cada um dos estados. O primeiro conjunto de dados foi obtido pelo SIDRA, ${ }^{4}$ do IBGE e o último da Pesquisa NAcional por Amostra de Domicílios (PNAD) Contínua de 2019.

Para a taxa de desconto intertemporal da utilidade, $\beta$, para todos os estados utilizamos o mesmo valor calculado por Rabelo e Soares (2020), equivalente a um valor estatístico da vida de R \$ 2,9 milhóes. Como indicado pelos autores, este valor é baseado em estimativas recentes para o Brasil, de Ferrari et al. (2019) e Rocha et al. (2019).

Novamente, assim como em Eichenbaum et al. (2020), calibramos o valor do parâmetro que controla a produtividade relativa da população infectada, $\phi^{i}$, em 0,8 . Este valor é consistente com a ideia de que indivíduos sintomáticos não trabalham e com a hipótese de que $80 \%$ da população infectada é assintomática, conforme aponta o China Center for Disease Control and Prevention.

Em relação às probabilidades de descobrimento de tratamentos efetivos e vacinas, $\delta_{c}$ e $\delta_{v}$, respectivamente, seguindo Eichenbaum et al. (2020), as calibramos para refletir um tempo médio de descoberta de um ano.

TABELA 1

Principais valores utilizados para a calibragem dos parâmetros e variáveis de cada estado

\begin{tabular}{lrrrrr}
\hline Valor & São Paulo & Amazonas & Ceará & Rio de Janeiro & Pernambuco \\
\hline Imperial College IFR (\%) & 0,70 & 0,80 & 1,10 & 0,80 & 1,10 \\
Número de pessoas na força de trabalho, ocupadas & 22.782 .714 & 1.657 .700 & 3.764 .280 & 7.651 .617 & 3.602 .820 \\
Número de estudantes & 10.306 .000 & 1.284 .000 & 2.376 .000 & 3.853 .000 & 2.475 .000 \\
Horas diárias dedicadas aos cuidados de pessoas e/ou afazeres domésticos & 2,06 & 1,44 & 1,87 & 2,04 & 2,02 \\
Número médio de pessoas por domićlio & 2,80 & 3,60 & 3,10 & 2,70 & 2,90 \\
Tempo habitual de deslocamento para o trabalho dos indivíduos (minutos) & 37,15 & 33,95 & 26,60 & 43,07 & 30,52 \\
População do estado & 45.919 .049 & 4.144 .597 & 9.132 .078 & 17.264 .943 & 9.557 .071 \\
Média de horas habitualmente trabalhadas por dia em todos os trabalhos & 8,24 & 7,30 & 7,58 & 8,10 & 7,74 \\
Rendimento médio mensal real domiciliar per capita, a preços médios do ano & 1.889 & 838 & 939 & 1.809 & 954 \\
\hline
\end{tabular}

Elaboração dos autores.

4. Tabela 6373. 
TABELA 2

Valores calibrados para as principais variáveis e parâmetros de cada estado

\begin{tabular}{|c|c|c|c|c|c|}
\hline Parâmetro/variável & São Paulo & Amazonas & Ceará & Rio de Janeiro & Pernambuco \\
\hline $\boldsymbol{\kappa}$ & 0,63 & 1,10 & 2,35 & 1,33 & 1,90 \\
\hline$\alpha_{1}$ & 0,16 & 0,28 & 0,30 & 0,12 & 0,25 \\
\hline$\alpha_{2}$ & 0,17 & 0,13 & 0,14 & 0,16 & 0,14 \\
\hline$\alpha_{3}$ & 0,66 & 0,60 & 0,56 & 0,71 & 0,61 \\
\hline$\pi_{1}$ & $4,28 \cdot 10^{-7}$ & $3,68 \cdot 10^{-6}$ & $3,17 \cdot 10^{-6}$ & $8,53 \cdot 10^{-7}$ & $2,59 \cdot 10^{-6}$ \\
\hline$\pi_{2}$ & $5,99 \cdot 10^{-5}$ & $5,54 \cdot 10^{-5}$ & $5,85 \cdot 10^{-5}$ & $5,13 \cdot 10^{-5}$ & $5,33 \cdot 10^{-5}$ \\
\hline$\pi_{3}$ & 0,39 & 0,35 & 0,33 & 0,33 & 0,36 \\
\hline \multirow{2}{*}{$\varepsilon$} & 100 & 100 & 100 & 100 & 100 \\
\hline & $\overline{45.919 .049}$ & $\overline{4.144 .597}$ & 9.132 .078 & 17.264 .943 & $\overline{9.557 .071}$ \\
\hline $\boldsymbol{A}$ & 11,46 & 5,74 & 6,19 & 11,17 & 6,16 \\
\hline $\boldsymbol{\theta}$ & $5,89 \cdot 10^{-4}$ & $7,51 \cdot 10^{-4}$ & $6,96 \cdot 10^{-4}$ & $6,10 \cdot 10^{-4}$ & $6,68 \cdot 10^{-4}$ \\
\hline$\beta$ & 0,966 & 0,966 & 0,966 & 0,966 & 0,966 \\
\hline$\phi^{i}$ & 0,80 & 0,80 & 0,80 & 0,80 & 0,80 \\
\hline
\end{tabular}

\section{EQUILÍBRIO COMPETITIVO}

Neste primeiro exercício, apresentamos resultados para o equilíbrio competitivo de cada estado. No equilíbrio competitivo não ocorrem quaisquer tentativas, por parte das autoridades, de se conter a dinâmica de evolução da epidemia. A dinâmica da epidemia é afetada apenas pelas próprias decisóes dos agentes econômicos, que têm a liberdade de reduzir as suas probabilidades de serem infectados, reduzindo consumo e horas trabalhadas.

A figura 1 apresenta, em nível, a dinâmica da evolução da epidemia para cada um dos cinco estados, assim como seu efeito sobre os agregados de consumo e horas de trabalho ofertadas em cada um deles no equilíbrio competitivo. A figura 2 apresenta os mesmos resultados, porém em proporção da população inicial de cada estado. 
Tratemos primeiro de observações gerais sobre os resultados. A dinâmica geral do modelo ocorre da seguinte forma: a partir de uma populaçáo inicial de 100 infectados a dinâmica da epidemia tem seu início para os cinco estados. A população de infectados cresce, até eventualmente atingir um pico. Conforme a população de infectados cresce, a população de suscetíveis diminui. Para os infectados, só há dois destinos possíveis, a saber, a recuperação ou a morte. Assim, conforme a população de infectados cresce, a população de recuperados e a quantidade de mortos também, em alguma medida, inevitavelmente aumenta. $\mathrm{Na}$ ausência da descoberta de vacinas, a única forma da epidemia chegar ao fim é infectando parcela suficiente da população para que seja alcançada a chamada imunidade de rebanho. O tamanho desta parcela depende de caraterísticas particulares do vírus causador da epidemia. Para a Covid-19, não há ainda consenso quanto a essa parcela. Para este trabalho assumimos, assim como Eichenbaum et al. (2020), que a imunidade de rebanho é alcançada quando $60 \%$ da população é infectada. Não obstante, como o modelo incorpora a probabilidade de descoberta de vacina, conforme será visto, os estados, em média, chegarão ao fim da epidemia com menos de $60 \%$ de suas populaçóes infectadas pelo vírus. Do ponto de vista econômico, a dinâmica das epidemias induz recessóes. $\mathrm{O}$ consumo agregado de todos os estados cai, refletindo, em primeiro lugar, numa menor produtividade da populaçáo infectada, gerando um efeito renda negativo que reduz o consumo desta parcela da população e, em segundo lugar, a reduçáo permanente da força de trabalho decorrente das mortes.

Agora, descrevemos os resultados de cada estado em particular. A parcela da populaçáo inicial do estado de São Paulo infectada atinge seu pico em 4,95\% (2.271.910 infectados), sendo este o maior pico entre os cinco estados. O segundo maior pico ocorre no Amazonas, com 4,21\% da população inicial infectada (174.441 infectados). A seguir, Pernambuco, com 4,06\% (387.726 infectados); Rio de Janeiro, com 3,83\% (660.400 infectados); e, por último, apresentando o menor dos cinco picos, o Ceará, com 3,83\% da população inicial infectada (331.309). O pico de infectados ocorre primeiro no Amazonas, com 39,33\% do progresso do tempo total da epidemia ocorrido, depois em Pernambuco, com $42 \%$, prossegue então para ocorrer no Ceará, com 42,67\%, Rio de Janeiro, com $46 \%$ e, apenas por último, em Sáo Paulo, com 47,33\% do progresso de tempo da epidemia ocorrido. Os picos das taxas de mortalidade ocorrem nestes mesmos momentos e, portanto, seguem esta mesma ordem de ocorrência no tempo. 
Entre os cinco estados analisados, os choques macroeconômicos são mais severos nos estados de Ceará e Pernambuco. No Ceará, os agregados de consumo e horas de trabalho ofertadas sofrem uma queda de aproximadamente $18,11 \% \mathrm{em}$ relação ao estado estacionário pré-epidêmico, enquanto que em Pernambuco, a queda é de aproximadamente 17,66\%. A severidade destes choques pode ser explicada, em parte, pela baixa capacidade de seus sistemas de saúde, refletida na dinâmica de crescimento de suas taxas de mortalidade. Tendo conhecimento desta situação, os indivíduos internalizam o crescimento destas taxas e respondem abrindo mão de consumo e trabalho para reduzir suas probabilidades de serem infectados, o que por sua vez aprofunda a recessão econômica.

No Rio de Janeiro são observadas quedas de 15,80\% do consumo agregado e do agregado de horas de trabalho ofertadas em relação ao estado estacionário pré-epidêmico, enquanto no estado de Amazonasa queda é de 13,67\%. O menos severo dos choques macroeconômicos ocorre em Sáo Paulo. Neste estado, as quedas do consumo agregado e do agregado de horas de trabalho tem início mais tarde, atingindo um vale de $13,55 \%$. São Paulo não apenas apresenta quedas menos severas como também menos duradouras. A recuperação ocorre rapidamente, acompanhando de perto a recuperação dos demais estados que sofreram quedas mais profundas.

Em relação ao tempo, o vale da recessão ocorre primeiro no Amazonas, quando o progresso do tempo total da epidemia atinge 38,67\%, depois em Pernambuco, em $41,33 \%$ do progresso, para então alcançar o Ceará, em 42,00\%, o Rio de Janeiro, em $45,33 \%$, e, finalmente, São Paulo, em 46,00\% do progresso do tempo total da epidemia. Assim, no equilíbrio competitivo o estado de São Paulo apresenta o início de retomada da economia mais tardio, enquanto o estado de Amazonas o mais precoce.

A epidemia tem seu fim com 52,93\% da população de Sáo Paulo infectada, sendo este o estado que atinge a maior parcela da população infectada entre os cinco estados analisados no equilíbrio competitivo (24.304.105 infectados). O estado com a segunda maior parcela da população infectada é o Amazonas, com 49,66\% (2.058.181 infectados); seguido por Pernambuco, com 49,16\% (4.698.514 infectados) e Rio de Janeiro, com 47,87\% (8.264.678 infectados). O Ceará apresenta a menor parcela entre os cinco estados, com $47,12 \%$ da população infectada ao fim da epidemia (4.302.928 infectados). 
Como resultado, a parcela da população inicial de Pernambuco acometida pela morte é de $0,36 \%$, sendo este o estado com a maior parcela da população morta (124.101 mortos). O segundo estado que mais sofre mortes em proporção da população inicial é o Ceará, com $0,34 \%$ de sua população acometida pela morte (11.660). Em seguida vêm Amazonas, com 0,28\% (31.144 mortos); Rio de Janeiro, com 0,27\% (46.800 mortos); e São Paulo, também com 0,27\% (34.221 mortos).

Os resultados apresentam, portanto, evidências de diferenças relevantes na dinâmica epidêmica de cada estado no equilíbrio competitivo em decorrência de suas diferenças intrínsecas. Não apenas o tamanho do pico de infectados e o tempo necessário para alcança-lo são diferentes em cada estado, como a profundidade e a duraçáo das recessóes, a parcela da populaçáo total infectada e a parcela da população inicial acometida pela morte ao fim da epidemia em cada estado também diferem entre eles.

Na próxima seção trataremos de analisar políticas ótimas de contenção que podem ser adotadas pelos estados para melhorar os resultados obtidos no equilíbrio competitivo. Na seção 6 analisamos os resultados sob o cenário de adoção destas políticas e comparamos com os resultados apresentados nesta seção para avaliar os efeitos da adoção destas medidas.

FIGURA 1

Modelo SIR-macro: resultados para o equilíbrio competitivo

(Em nível)
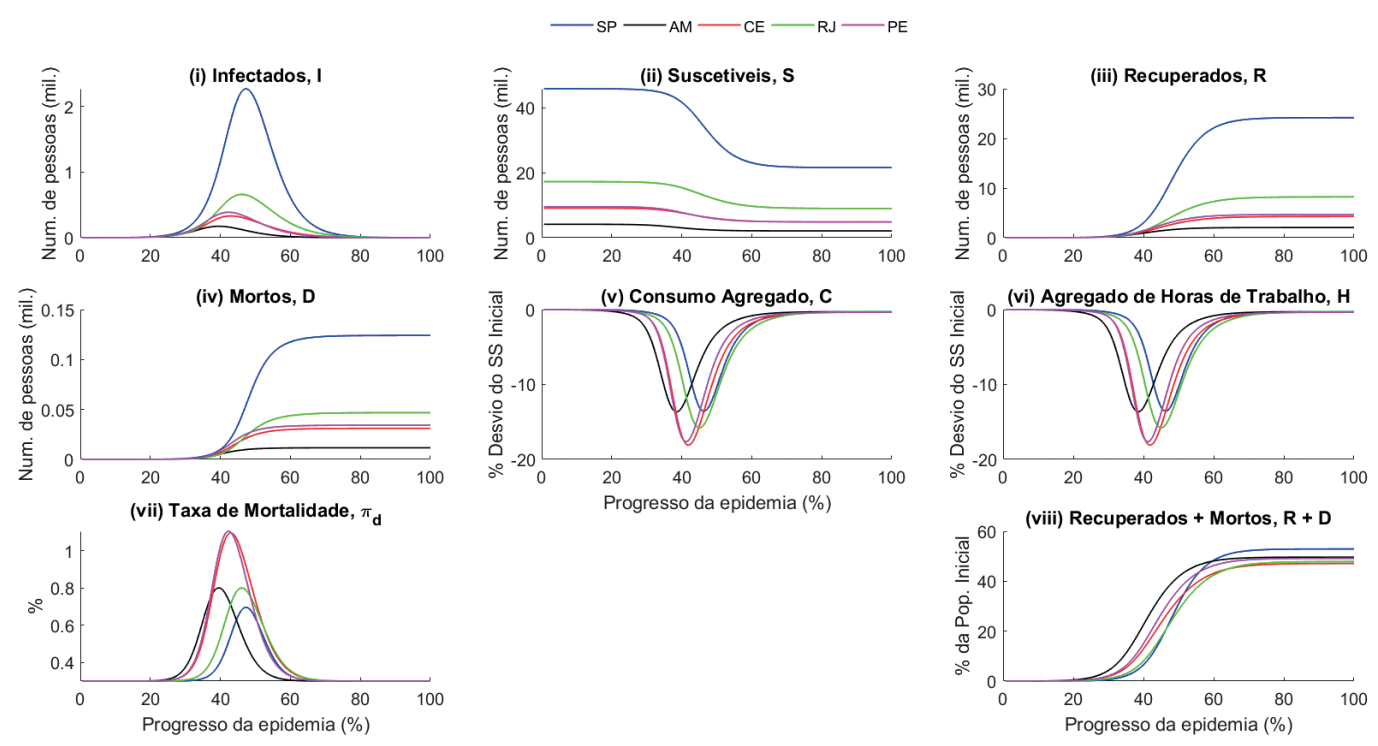

Elaboração dos autores.

Obs.: Figura cujos leiaute e textos não puderam ser padronizados e revisados em virtude das condições técnicas dos originais (nota do Editorial). 
FIGURA 2

Modelo SIR-macro: resultados para o equilíbrio competitivo

(Em \% da população inicial)

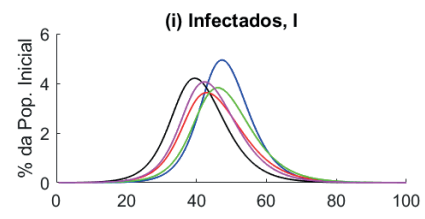
$-\mathrm{SP}-\mathrm{AM}-\mathrm{CE}-\mathrm{RJ}-\mathrm{PE}$
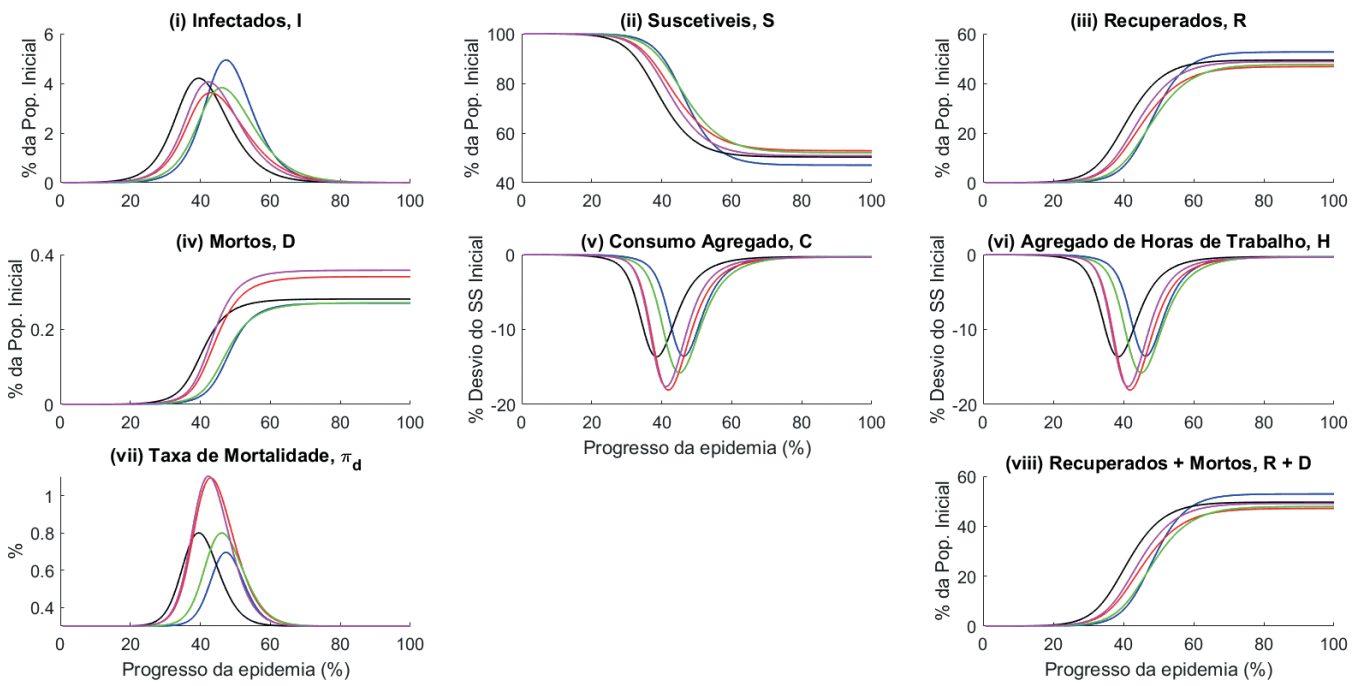

Elaboração dos autores.

Obs.: Figura cujos leiaute e textos não puderam ser padronizados e revisados em virtude das condições técnicas dos originais (nota do Editorial).

\section{POLÍTICA DE CONTENÇÃO}

Nesta seção, inspirados pelo trabalho de Eichenbaum et al. (2020), consideramos um simples problema de Ramsey para lidar com uma clássica externalidade associada ao comportamento dos agentes infectados no equilíbrio competitivo: como os agentes são atomísticos, eles não levam em conta o impacto de suas ações sobre as taxas de infecção e mortalidade dos demais agentes. Por esta razão, o equilíbrio competitivo do modelo não é socialmente ótimo.

Conforme apontado por Eichenbaum et al. (2020), assim como em qualquer outro problema de Ramsey, é preciso avaliar quais são os instrumentos de política disponíveis para mitigá-lo. $\mathrm{Na}$ prática, existem muitas maneiras pelas quais os governantes podem reduzir interações sociais. Podem ser citados como exemplos de medidas de contenção ordens de abrigo no local (shelter-in-place) e interrupçóes obrigatórias do funcionamento de restaurantes, bares e serviços não-essenciais em geral. Eichenbaum et al. (2020) modelam, inspirados no trabalho de Farhi e Werning 
(2012), as medidas de contenção como taxaçôes sobre o consumo que são reembolsadas aos indivíduos por meio de transferências lump sum. Procedemos, assim como Eichenbaum et al. (2020) modelando desta forma. Referimo-nos a estas taxas como taxas de contenção.

Para mitigar o problema de Ramsey, o objetivo desta seção é computar, para cada estado, a sequência ótima de 250 taxas de contenção $\left\{\mu_{t}\right\}_{t=0}^{249}$ que maximiza o bem-estar social, $U_{0}$, definido como sendo a média ponderada das utilidades dos diferentes indivíduos. Como no período inicial $t=0, R_{0}=D_{0}=0$, o valor de $U_{0}$ é

$$
U_{0}=S_{0} U_{0}^{S}+I_{0} U_{0}^{i}
$$

Dada a sequência de taxas de contenção, resolvemos o modelo para o equilíbrio competitivo e avaliamos a função de bem-estar social, iterando essa sequência até obter a solução ótima.

$\mathrm{Na}$ figura 3 estáo apresentados os resultados, em nível, para o cenário em que todos os estados adotam políticas ótimas de contenção. $\mathrm{Na}$ figura 4 estão apresentados os mesmos resultados, porém em porcentagem da população inicial.

Assim como na seção anterior, iniciaremos aqui com uma observação geral dos resultados. As trajetórias ótimas de contenção sempre escalam gradualmente, elevando-se ao longo do tempo e seguindo quase que paralelamente a dinâmica das taxas de infecçóes. Este fenômeno foi notado por Eichenbaum et al. (2020) e, conforme explicam estes autores, a sua intuição é a seguinte: as medidas de contenção internalizam as margens externas causadas pelo comportamento da população infectada. Por exemplo, no período inicial $t=0$ a população de infectados é muito pequena, de modo que a externalidade é pouco importante. Uma taxa de contenção muito alta em $t=0$ resultaria em um elevado custo social em troca de poucos benefícios. Conforme a população de infectados aumenta, a importância da externalidade eleva-se, tornando-se cada vez mais preocupante. Como resposta, a taxa ótima de contenção aumenta. Outra razão que justifica a inadequação de taxas de contenção demasiadamente altas em $t=0$ e persistentes é que, na ausência do descobrimento de vacinas, a única maneira de prevenir a recorrência da epidemia 
é fazendo com que uma parcela suficiente da população adquira imunidade, infectando-se e recuperando-se. A maneira ótima de alcançar este nível crítico de imunidade de rebanho é elevando gradualmente as medidas de contenção conforme as infecçóes crescem e relaxando e reduzindo-as lentamente conforme novos casos de infecção declinam.

Isto posto, prossigamos agora para a descrição particular dos resultados. Primeiro, já no período $t=0$, onde a populaçáo de infectados de cada estado alcança o nível de 100 indivíduos, as taxas de contenção de Ceará, Amazonas, Pernambuco, Rio de Janeiro e São Paulo já se apresentam nos níveis de, respectivamente, 16,12\%, 16,10\%, $15,96 \%, 15,77 \%$ e $14,05 \%$. Esses números mostram que o estado que requer medidas de contenção mais drásticas já no início da epidemia (quando o centésimo infectado é alcançado), relativamente aos demais estados analisados, é o Ceará, enquanto o que requer medidas menos severas é o estado de São Paulo. Estes resultados oferecem evidências de que as diferenças intrínsecas de cada estado fazem com que as decisóes iniciais relativas à severidade das medidas de contenção a serem adotadas difiram para cada estado. Náo obstante, os resultados mostram que a decisão ótima por parte das autoridades de todos os estados é a adoção de medidas de contenção significativas desde o início da epidemia.

Entre os cinco estados, o que atinge o pico mais alto da taxa de contenção é Pernambuco, com uma taxa de contençáo de $53,40 \%$. O segundo mais alto pico ocorre no Ceará, onde a taxa de contenção atinge $48,35 \%$. Em terceiro, o Amazonas atinge um pico da taxa de contenção de 43,68\% e, em quarto, o Rio de Janeiro com 39,54\%. São Paulo é o estado que tem a menor taxa de contenção no pico, em $38,76 \%$.

O pico da taxa de contenção ocorre primeiro no Amazonas, em 40,67\% do progresso do tempo total da epidemia. Este é, portanto, o primeiro estado a começar a relaxar as medidas de contenção. Em seguida, o pico ocorre em Pernambuco, com $44 \%$ do progresso de tempo total de epidemia, depois no Ceará, com $46 \%$ do progresso da epidemia ocorrido, então em Sáo Paulo com 47,33\% e, finalmente, no Rio de Janeiro, com 48,67\% do progresso da epidemia ocorrido. O Rio de Janeiro é, portanto, o último estado a atingir o pico da taxa de contenção e, consequentemente, também o último a iniciar o processo de retomada da economia. 
Estes resultados mostram que as diferenças intrínsecas de cada estado não apenas afetam a severidade inicial das medidas de contenção adotadas por cada um deles como também a dinâmica da evolução destas taxas de contenção no tempo, implicando diferenças no momento ideal em que as medidas de contenção precisarão ser elevadas, até onde elas precisarão ser elevadas e quando poderão ser finalmente relaxadas. Novamente, não obstante a estas diferenças interestaduais de condução ótima das políticas de contenção, todos os resultados apontam como decisões ótimas para cada um dos cinco estados a adoção de medidas de contenção relativamente severas.

Nesta seção estudamos as políticas ótimas de contenção a serem adotadas por cada um dos cinco estados analisados. Não obstante, não foram analisadas as consequências da adoção destas políticas ótimas. Na próxima seção serão analisadas essas consequências, sob várias dimensóes, em relação ao equilíbrio competitivo exposto na seção anterior.

FIGURA 3

Modelo SIR-macro: resultados sob a adoção de políticas ótimas de contenção (Em nível)
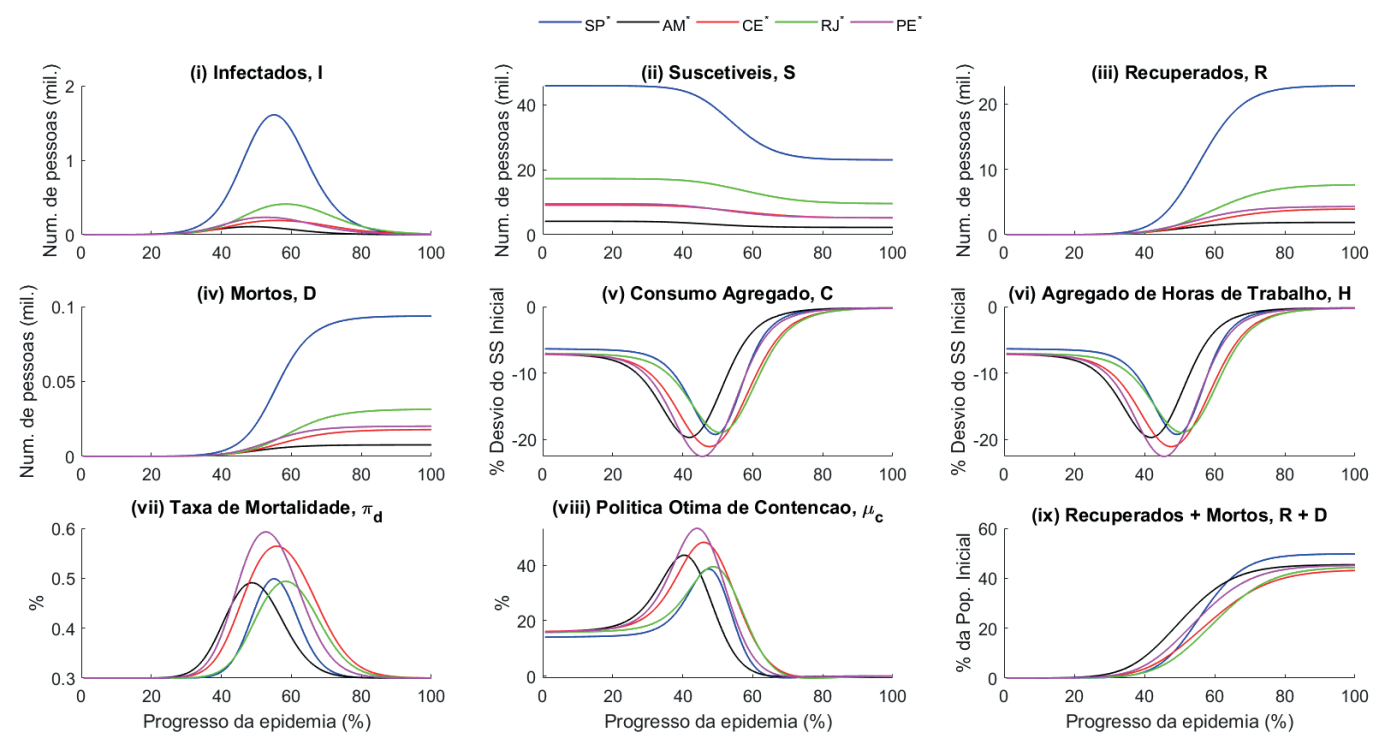

Elaboração dos autores.

Obs.: Figura cujos leiaute e textos não puderam ser padronizados e revisados em virtude das condições técnicas dos originais (nota do Editorial). 
FIGURA 4

Modelo SIR-macro: resultados sob a adoção de políticas ótimas de contenção

(Em \% da população inicial)
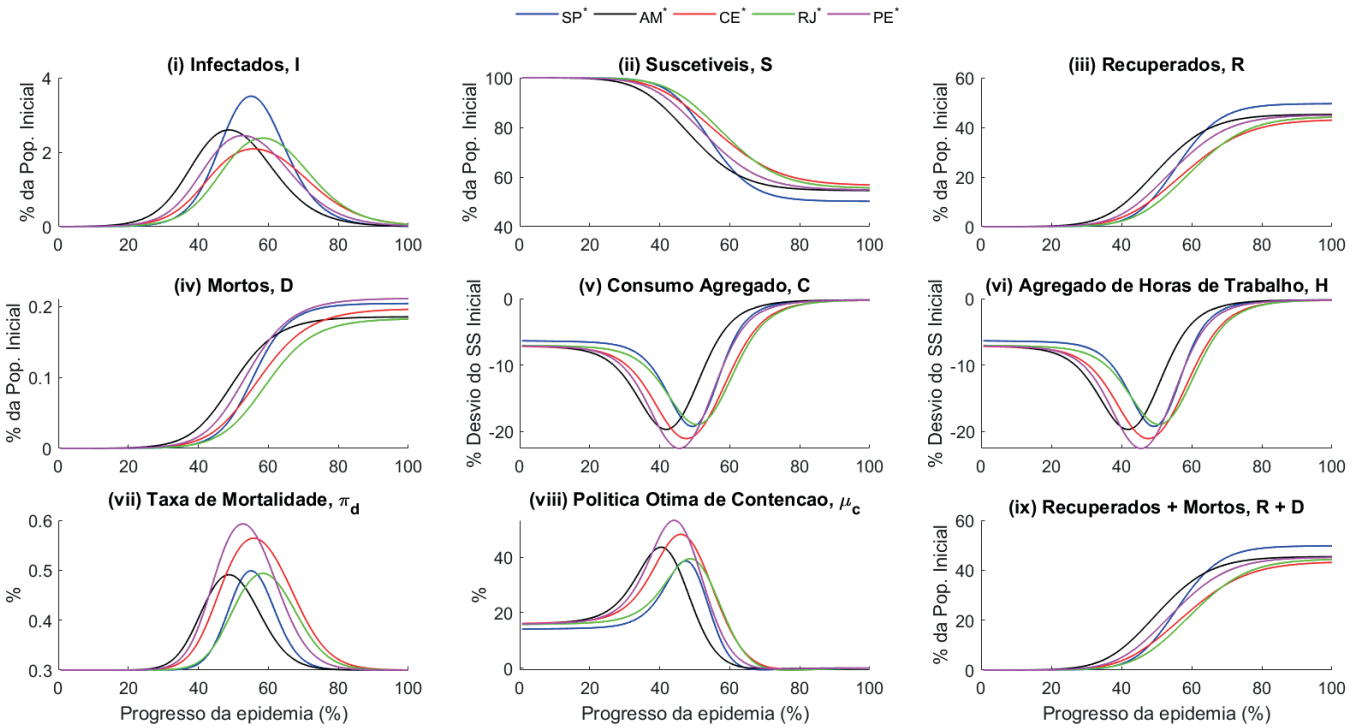

Elaboração dos autores.

Obs.: Figura cujos leiaute e textos não puderam ser padronizados e revisados em virtude das condições técnicas dos originais (nota do Editorial).

\section{AS CONSEQUÊNCIAS DA POLÍTICA ÓTIMA DE CONTENÇÃO}

Todos os resultados que descreveremos aqui estáo resumidos na tabela 3. A tabela 4 resume os efeitos da adoçáo de políticas ótimas de contençáo pelos estados em relação ao cenário de equilíbrio competitivo. A tabela 5 apresenta, para cada cenário, os momentos do progresso da epidemia em que ocorrem os principais picos e vales nos resultados de cada estado.

No cenário em que os cinco estados adotam políticas ótimas de contenção, São Paulo é o estado que atinge o maior pico de infectados, com 3,50\% da populaçáo inicial infectada (1.608.921 infectados). O Amazonas registra 2,60\% (107.708 infectados); Pernambuco registra 2,45\% (234.004 infectados); e o Rio de Janeiro atinge um pico de $2,38 \%$ de sua população infectada (410.857 infectados). Por fim o Ceará que é o estado que atinge o menor pico de infectados, atinge um pico de 2,09\% de sua população infectada (190.939 infectados). 
Esses novos valores implicam, em relação ao equilíbrio competitivo, uma redução do pico de infectados de 1,61 ponto percentual (p.p.) da população inicial para o Amazonas e Pernambuco, sendo estes dois os que sofrem os maiores efeitos de achatamento da curva em decorrência da adoção de políticas ótimas de contenção. A terceira maior redução do pico de infectados ocorre no Ceará, com uma redução de 1,54 p.p.; seguido pelo Rio de Janeiro, com uma redução de 1,45 p.p.; e, finalmente, por São Paulo, com uma redução de 1,44 p.p. - a menor entre os cinco. Estes números significam 66.732 infectados a menos no pico para o Amazonas, 386.552 a menos para Pernambuco, 140.369 a menos para o Ceará, 249.541 a menos para o Rio de Janeiro, e 662.988 infectados a menos no pico para São Paulo.

Em relação ao momento da ocorrência dos picos de infectados, estes passam a ocorrer em 48,67\% do progresso do tempo total da epidemia no Amazonas; em 52,67\% do progresso em Pernambuco; 55,33\% em São Paulo; 56,00\% no Ceará; e 58,67\% do progresso do tempo total no Rio de Janeiro. Isto implica que as políticas ótimas de contenção, no momento de progresso total da epidemia, atrasam em 9,33 p.p. o pico de infectados no Amazonas; enquanto em Pernambuco o atraso é de 10.67 p.p.. Em São Paulo, o atraso é de 8 p.p.; enquanto no Ceará é de 13,33 p.p.; seguido pelo Rio de Janeiro, com um atraso de 12,67 p.p.. Isto significa que o estado que sofre o maior prolongamento do tempo até o pico de infectados, em decorrência da adoção de políticas ótimas de contenção, é o Ceará, enquanto que o que sofre o menor prolongamento é o estado de São Paulo. Como consequência, São Paulo, que no equilíbrio competitivo era o último entre os cinco a atingir o pico, passa a ser o terceiro. O Ceará passa de terceiro para quarto e o Rio de Janeiro de quarto para o último estado a atingir o pico. Amazonas e Pernambuco continuam a ser, assim como no cenário de equilíbrio competitivo, respectivamente o primeiro e o segundo estado a atingir o pico.

Estes resultados apresentam evidências de que as diferenças intrínsecas entre os estados influenciam relevantemente o efeito da adoção das políticas ótimas de contenção, afetando de maneira heterogênea o pico da curva de infectados, bem como sua dinâmica temporal.

Com relação aos choques macroeconômicos sobre os agregados de consumo e horas de trabalho, com a adoção das políticas ótimas de contenção há um agravamento da recessão para todos os estados. Para Pernambuco a queda no consumo agregado e no agregado de horas de trabalho ofertadas passa a ser de 22,58\%; para o Ceará, de 21,10\%; para o Rio de Janeiro, de 18,98\%; para o Amazonas, de 19,72\%; e para São Paulo, de 19,28\%. Esses valores implicam que as políticas ótimas de contenção 
aprofundam as recessões, no estado estacionário pré-epidêmico, com quedas de 4,92 p.p. para Pernambuco; 3 p.p. para o Ceará; 3,18 p.p. para o Rio de Janeiro; 6,06 p.p. para o Amazonas; 5,73 p.p. para Sáo Paulo. Como pode ser observado, entre os cinco estados analisados, o que sofre o maior impacto macroeconômico decorrente da adoção de uma política ótima de contenção é o Amazonas, enquanto o que sofre o menor impacto é o Ceará. Como consequência destes efeitos heterogêneos, Pernambuco, que no equilíbrio competitivo era o estado que sofria o segundo maior impacto macroeconômico entre os cinco estudados, passa a ser o que sofre o maior impacto. Ceará, que sofria o maior impacto, passa a ser o que sofre o segundo maior impacto. Amazonas passa de quarto para terceiro, Sáo Paulo de último para quarto e o Rio de Janeiro passa de terceiro maior impacto no equilíbrio competitivo para o quinto e menor impacto macroeconômico no cenário de adoção de políticas ótimas.

O momento dos vales dos agregados de consumo e horas de trabalho após a adoção de políticas ótimas de contenção passam a ocorrer, respectivamente, em 42,00\% do progresso do tempo total da epidemia no Amazonas; 45,33\% do tempo total em Pernambuco; 47,33\% no Ceará; 49,33\% em Sáo Paulo; e 50,67\% do progresso do tempo total no Rio de Janeiro. Isto implica um aumento da duração da recessão de 3,33 p.p. para o Amazonas; 4, p.p. para Pernambuco; 5,33 p.p. para o Ceará; 3,33 p.p. para São Paulo; e 5,33 p.p. para o Rio de Janeiro. Como pode ser visto, os efeitos são heterogêneos. Ceará e Rio de Janeiro são os estados que sofrem o maior prolongamento da duração da recessão em decorrência da adoção de políticas ótimas de contenção; enquanto Pernambuco sofre um efeito intermediário. São Paulo e Amazonas são os que sofrem menos. Como consequência destes efeitos heterogêneos, São Paulo, que no equilíbrio competitivo era o último dos cinco estados a atingir o vale da recessão e iniciar a retomada da economia, passa a ser o quarto; enquanto o Rio de Janeiro, que era o quarto, passa a ser o quinto e último dos cinco estados a iniciar a retomada econômica.

A epidemia passa a ter seu fim com 49,74\%, da população inicial de São Paulo infectada, sendo este o estado com a maior parcela da populaçáo inicial infectada (22.841.118 infectados). Em segundo lugar, consta o Amazonas, com 45,42\% da população inicial infectada (1.882.424 infectados). Em terceiro, consta Pernambuco com, 45,12\% (4.311.96 infectados); seguido pelo Rio de Janeiro, com 44,29\% (7.647.286 infectados); e Ceará, com 43,11\% (3.936.502 infectados). Estes números representam, em relação ao equilíbrio competitivo, uma redução da população total infectada (baseada na população inicial) resultante da epidemia de 3,19 p.p. para Sáo Paulo; 4,24 p.p. para o Amazonas; 4,04 p.p. para Pernambuco; 3,58 p.p. para o Rio de Janeiro; e 4,01 p.p. para o Ceará. Assim, ao fim da epidemia, há 1.462.987 infectados a menos em São 
Paulo; 175.757 a menos no Amazonas; 386.552 a menos em Pernambuco; 617.392 no Rio de Janeiro; e 366.425 infectados a menos no Ceará. Como pode ser visto, os efeitos da adoção de políticas ótimas de contenção sobre a parcela total da população inicial infetada ao fim da epidemia são bastante heterogêneos entre os estados. O estado que sofre a maior redução desta parcela em decorrência da adoção de políticas ótimas de contenção é o Amazonas, que é seguido por Pernambuco, Ceará, Rio de Janeiro e, finalmente, São Paulo, que apresenta a menor redução entre os cinco estados.

A maior parcela da populaçáo inicial que passa a ser acometida pela morte ocorre em Pernambuco, onde alcança 0,21\% (20.163 mortos). Em segundo lugar, encontram-se as parcelas dos estados de São Paulo e Ceará, que alcançam 0,20\% da população inicial (93.693 e 17.884 mortos, respectivamente). Em terceiro, a do estado do Amazonas, de 0,19\% (7.676 mortos); e, em último, a do estado do Rio de Janeiro, de 0,18\% da população inicial infectada (31.433 mortos). Estes números representam, em relação ao equilíbrio competitivo, reduçóes no número de mortos de 0,16 p.p. em Pernambuco; 0,07 p.p. em São Paulo; 0,15 p.p. no Ceará; 0,10 p.p. no Amazonas; e 0,09 p.p. no Rio de Janeiro. Essas reduçóes se traduzem em 14.057 vidas salvas em Pernambuco, 30.408 vidas salvas em São Paulo, 13.260 vidas salvas no Ceará, 3.984 vidas salvas no Amazonas e 15.366 vidas salvas no Rio de Janeiro. Conforme pode ser visto, os efeitos da adoção de políticas ótimas de contenção sobre a parcela da população inicial acometida pela morte, para cada estado, são também bastante heterogêneos. $\mathrm{O}$ maior efeito ocorre em Pernambuco, que é seguido por Ceará, Amazonas, Rio de Janeiro e, finalmente, por São Paulo, que sofre a menor redução da parcela da população inicial que é acometida pela morte. Como consequências destes efeitos heterogêneos, São Paulo, que no equilíbrio competitivo era o estado que apresentava a menor parcela da populaçáo inicial acometida pela morte ao fim da epidemia, passa a ser o detentor da terceira maior parcela entre os cinco estados. $\mathrm{O}$ Amazonas passa de terceira maior parcela para quarta e o Rio de Janeiro de quarta maior parcela para a menor parcela entre os cinco estados.

A Figura 5 apresenta o comparativo de resultados entre o equilíbrio competitivo e o cenário de política ótima para todos os estados em conjunto, em nível. A figura 6 apresenta os mesmos resultados, porém em porcentagem da populaçáo inicial. As Figuras figuras $7,8,9,10$ e 11 apresentam os comparativos de resultados entre o equilíbrio competitivo e o cenário de política ótima para cada um dos estados em separado, todos em nível. 


\section{FIGURA 5}

Modelo SIR-macro: comparativo de resultados entre os cenários de política ótima de contenção ${ }^{1}$ e equilíbrio competitivo ${ }^{2}$

(Em nível)
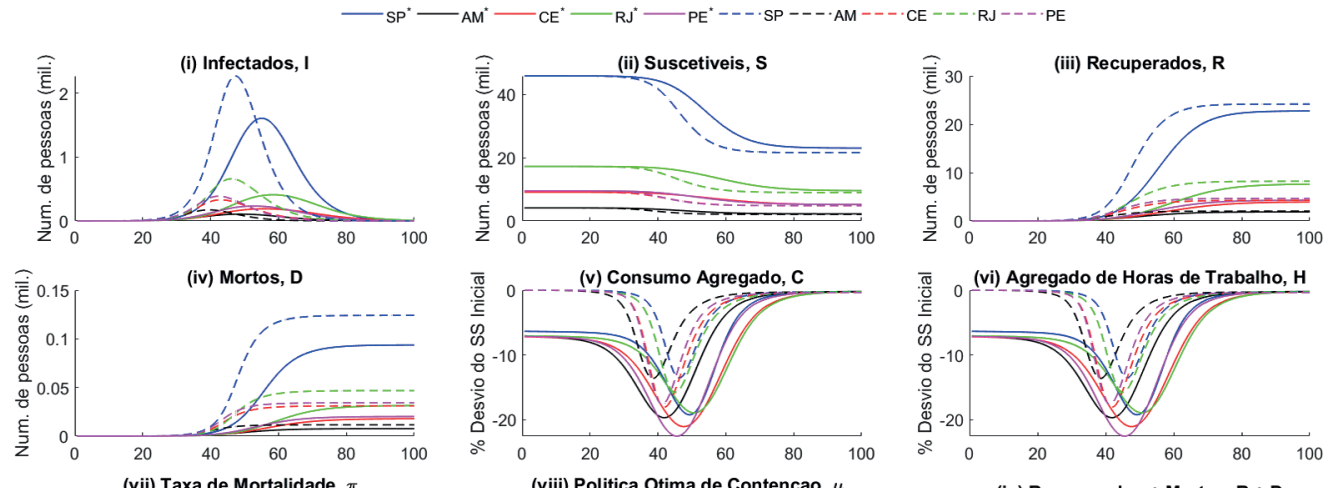

(vii) Taxa de Mortalidade, $\pi_{d}$
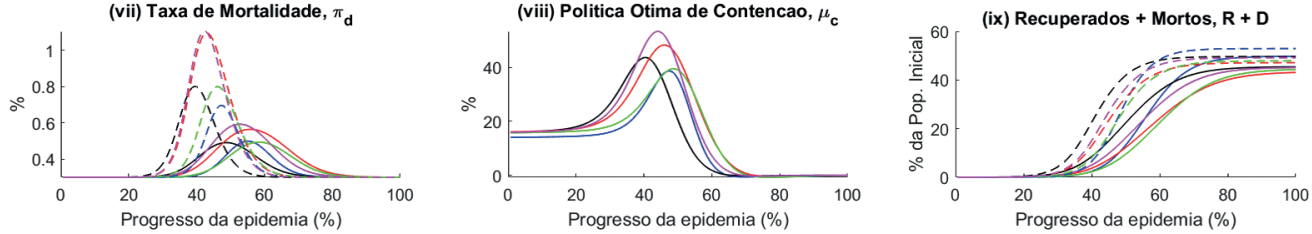

Elaboração dos autores

Obs.: Figura cujos leiaute e textos não puderam ser padronizados e revisados em virtude das condições técnicas dos originais (nota do Editorial).

Notas: ${ }^{1}$ Linha sólida.

${ }^{2}$ Linhas pontilhadas.

\section{FIGURA 6}

Modelo SIR-macro: comparativo de resultados entre os cenários de política ótima de contenção ${ }^{1}$ e equilíbrio competitivo ${ }^{2}$

(Em \% da população inicial) $-\mathrm{SP}^{*}-\mathrm{AM}^{*}-\mathrm{CE}^{*}-\mathrm{RJ}^{*}-\mathrm{PE}^{*}-\cdot-\mathrm{SP}-\cdots \cdot \mathrm{AM}-\cdots \cdot \mathrm{CE}-\cdots \cdot-\mathrm{RJ}-\cdots \cdot \mathrm{PE}$
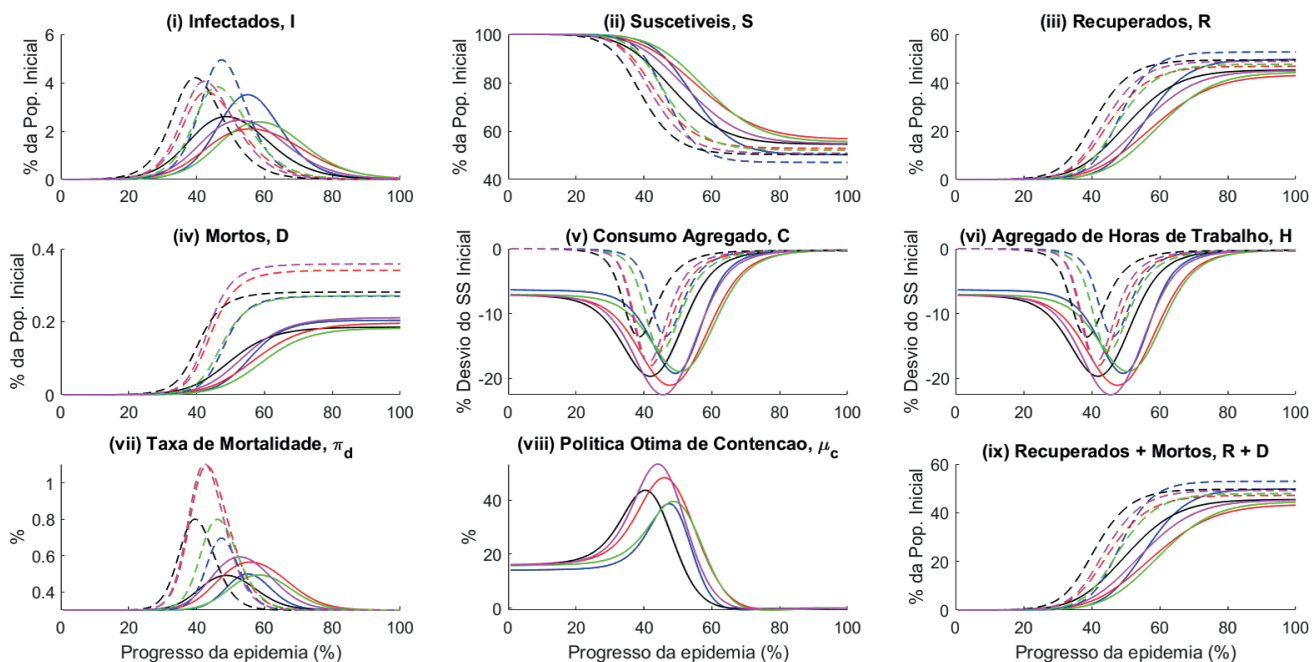

Elaboração dos autores.

Obs.: Figura cujos leiaute e textos não puderam ser padronizados e revisados em virtude das condições técnicas dos originais (nota do Editorial). Notas: ' Linha sólida.

${ }^{2}$ Linhas pontilhadas. 


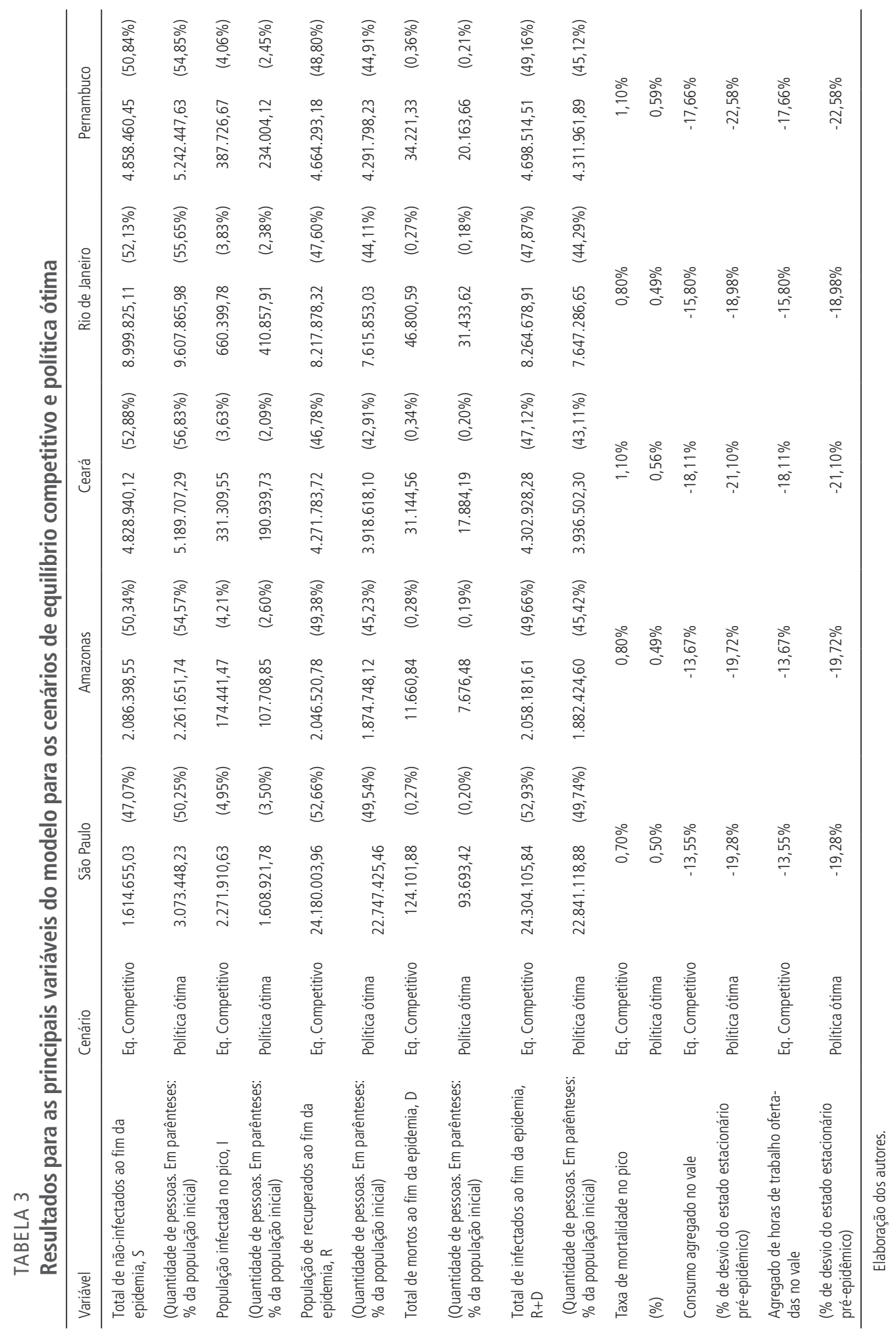

34 
TABELA 4

Efeitos da adoção de políticas ótimas de contenção pelos estados em relação ao cenário de equilíbrio competitivo

\begin{tabular}{|c|c|c|c|c|c|c|c|c|c|c|}
\hline Métrica & \multicolumn{2}{|c|}{ São Paulo } & \multicolumn{2}{|c|}{ Amazonas } & \multicolumn{2}{|c|}{ Ceará } & \multicolumn{2}{|c|}{ Rio de Janeiro } & \multicolumn{2}{|c|}{ Pernambuco } \\
\hline Pico da taxa de contenção (\%) & \multicolumn{2}{|c|}{$38,76 \%$} & \multicolumn{2}{|c|}{$43,68 \%$} & \multicolumn{2}{|c|}{$48,35 \%$} & \multicolumn{2}{|c|}{$39,54 \%$} & \multicolumn{2}{|c|}{$53,40 \%$} \\
\hline $\begin{array}{l}\text { Infectados evitados no pico } \\
\text { (Quantidade de pessoas. Em parênte- } \\
\text { ses: \% da populaçãa inicial) }\end{array}$ & 662.989 & $(1,44 \%)$ & 66.733 & $(1,61 \%)$ & 140.370 & $(1,54 \%)$ & 249.542 & $(1,45 \%)$ & 153.723 & $(1,61 \%)$ \\
\hline $\begin{array}{l}\text { Total de infectados evitados } \\
\text { (Quantidade de pessoas. Em parên- } \\
\text { teses: \% da população inicial) }\end{array}$ & 1.462 .987 & $(3,19 \%)$ & 175.757 & $(4,24 \%)$ & 366.426 & $(4,01 \%)$ & 617.392 & $(3,58 \%)$ & 386.553 & $(4,04 \%)$ \\
\hline $\begin{array}{l}\text { Redução do pico da taxa de morta- } \\
\text { lidade (\%) }\end{array}$ & \multicolumn{2}{|c|}{$-0,20 \%$} & \multicolumn{2}{|c|}{$-0,31 \%$} & \multicolumn{2}{|c|}{$-0,53 \%$} & \multicolumn{2}{|c|}{$-0,31 \%$} & \multicolumn{2}{|c|}{$-0,51 \%$} \\
\hline $\begin{array}{l}\text { Vidas salvas } \\
\text { (Quantidade de pessoas. Em parênte- } \\
\text { ses: \% da população inicial) }\end{array}$ & 30.408 & $(0,07 \%)$ & 3.984 & $(0,10 \%)$ & 3.260 & $(0,15 \%)$ & 15.367 & $(0,09 \%)$ & 14.058 & $(0,15 \%)$ \\
\hline $\begin{array}{l}\text { Efeito sobre o consumo agregado } \\
\text { no vale } \\
\text { (\% de desvio do estado estacionário } \\
\text { pré-epidêmico) }\end{array}$ & \multicolumn{2}{|c|}{$-5,73 \%$} & \multicolumn{2}{|c|}{$-6,06 \%$} & \multicolumn{2}{|c|}{$-2,99 \%$} & \multicolumn{2}{|c|}{$-3,18 \%$} & \multicolumn{2}{|c|}{$-4,92 \%$} \\
\hline $\begin{array}{l}\text { Efeito sobre o agregado de horas de } \\
\text { trabalho no vale } \\
\text { (\% de desvio do estado estacionário } \\
\text { pré-epidêmico) }\end{array}$ & \multicolumn{2}{|c|}{$-5,73 \%$} & \multicolumn{2}{|c|}{$-6,06 \%$} & \multicolumn{2}{|c|}{$-2,99 \%$} & \multicolumn{2}{|c|}{$-3,18 \%$} & \multicolumn{2}{|c|}{$-4,92 \%$} \\
\hline
\end{tabular}

Elaboração dos autores.

TABELA 5

Momentos do progresso da epidemia em que ocorrem os picos e vale das principais variáveis do modelo em cada cenário, para cada estado

(Em \%)

\begin{tabular}{|c|c|c|c|c|c|c|}
\hline Variável & Cenário & SP & AM & CE & RJ & PE \\
\hline $\begin{array}{l}\text { Momento do progresso da epidemia em que ocorre o pico de } \\
\text { Infectados, I }\end{array}$ & Eq. competitivo & 47,33 & 39,33 & 42,67 & 46,00 & 42,00 \\
\hline (\% de progresso do tempo total da epidemia) & Política ótima & 55,33 & 48,67 & 56,00 & 58,67 & 52,67 \\
\hline \multicolumn{7}{|l|}{ Momento do progresso da epidemia em que ocorre o picc } \\
\hline $\begin{array}{l}\text { taxa de contenção, } \boldsymbol{\mu}_{\boldsymbol{t}} \\
\text { (\% de progresso do tempo total da epidemia) }\end{array}$ & Política ótima & 47,33 & 40,67 & 46,00 & 48,67 & 44,00 \\
\hline $\begin{array}{l}\text { Momento do progresso da epidemia em que ocorre o pico da } \\
\text { taxa de mortalidade } \boldsymbol{\pi} \boldsymbol{}\end{array}$ & Eq. competitivo & 47,33 & 39,33 & 42,67 & 46,00 & 42,00 \\
\hline (em \% do tempo total de duração da epidemia) & Política ótima & 55,33 & 48,67 & 56,00 & 58,67 & 52,67 \\
\hline $\begin{array}{l}\text { Momento do progresso da epidemia em que ocorrem os vales } \\
\text { dos agregados de consumo e horas de trabalho }\end{array}$ & Eq. competitivo & 46,00 & 38,67 & 42,00 & 45,33 & 41,33 \\
\hline (em \% do tempo total de duração da epidemia) & Política ótima & 49,33 & 42,00 & 47,33 & 50,67 & 45,33 \\
\hline
\end{tabular}

Elaboração dos autores. 
FIGURA 7

Modelo SIR-macro: comparativo de resultados entre os cenários de política ótima de contenção ${ }^{1}$ e equilíbrio competitivo ${ }^{2}$ - São Paulo

(Em nível)
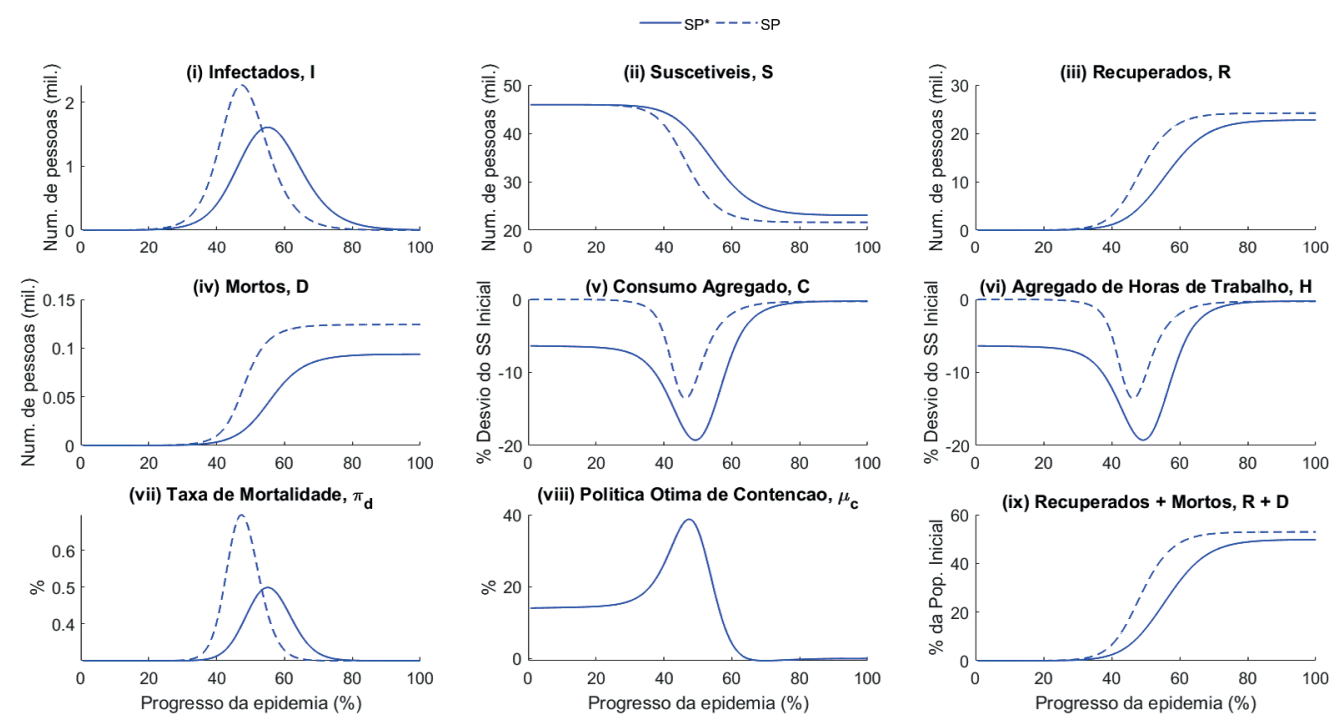

Elaboração dos autores.

Obs.: Figura cujos leiaute e textos não puderam ser padronizados e revisados em virtude das condições técnicas dos originais (nota do Editorial).

Notas: ' Linha sólida.

${ }^{2}$ Linhas pontilhadas.

FIGURA 8

Modelo SIR-macro: comparativo de resultados entre os cenários de política ótima de contenção ${ }^{1}$ e equilíbrio competitivo² - Amazonas

(Em nível)
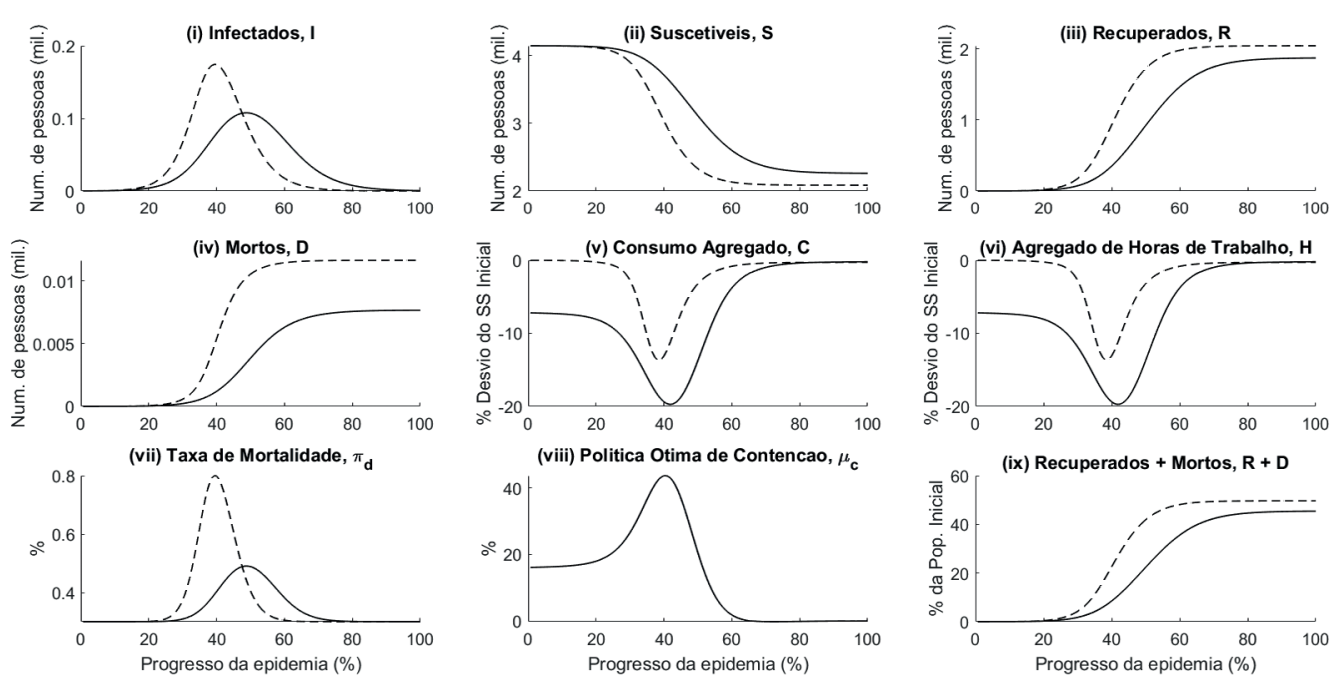

Elaboração dos autores.

Obs.: Figura cujos leiaute e textos não puderam ser padronizados e revisados em virtude das condições técnicas dos originais (nota do Editorial).

Notas: ' Linha sólida.

${ }^{2}$ Linhas pontilhadas. 
FIGURA 9

Modelo SIR-macro: comparativo de resultados entre os cenários de política ótima de contenção ${ }^{1}$ e equilíbrio competitivo² - Ceará

(Em nível)
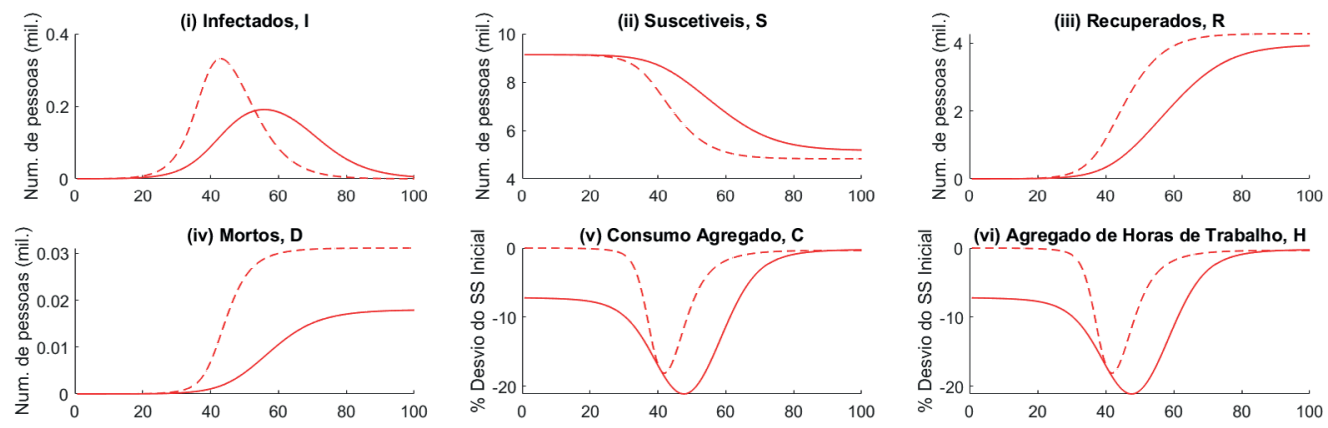

(vii) Taxa de Mortalidade, $\pi_{d}$
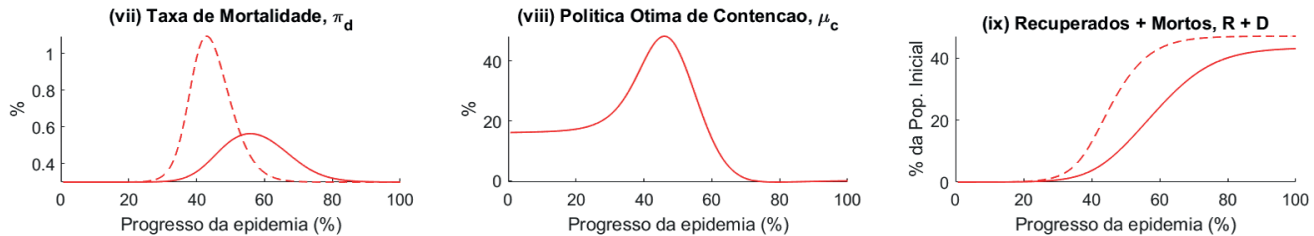

Elaboração dos autores.

Obs.: Figura cujos leiaute e textos não puderam ser padronizados e revisados em virtude das condições técnicas dos originais (nota do Editorial). Notas: ${ }^{1}$ Linha sólida.

${ }^{2}$ Linhas pontilhadas

FIGURA 10

Modelo SIR-macro: comparativo de resultados entre os cenários de política ótima de contenção ${ }^{1}$ e equilíbrio competitivo ${ }^{2}$ - Rio de Janeiro

(Em nível)
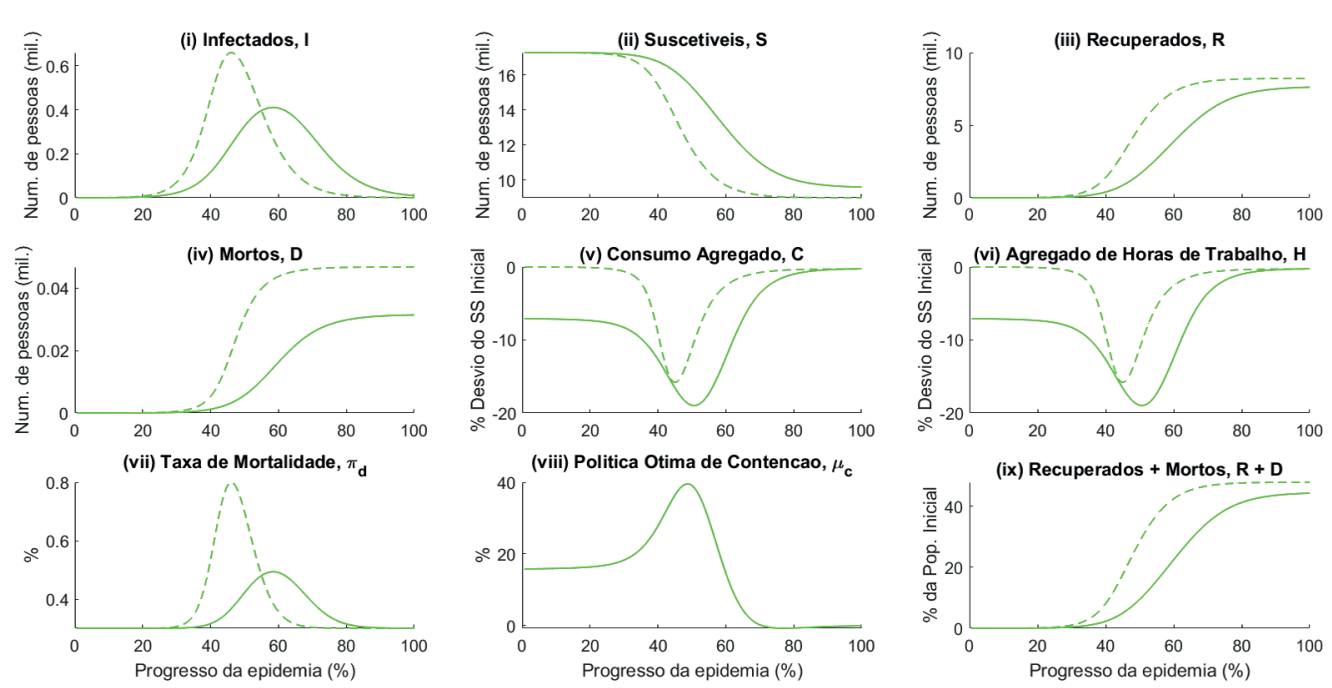

Elaboração dos autores.

Obs.: Figura cujos leiaute e textos não puderam ser padronizados e revisados em virtude das condições técnicas dos originais (nota do Editorial). Notas: ' Linha sólida.

${ }^{2}$ Linhas pontilhadas. 
FIGURA 11

Modelo SIR-macro: comparativo de resultados entre os cenários de política ótima de contenção $0^{1}$ e equilíbrio competitivo² - Pernambuco

(Em nível)
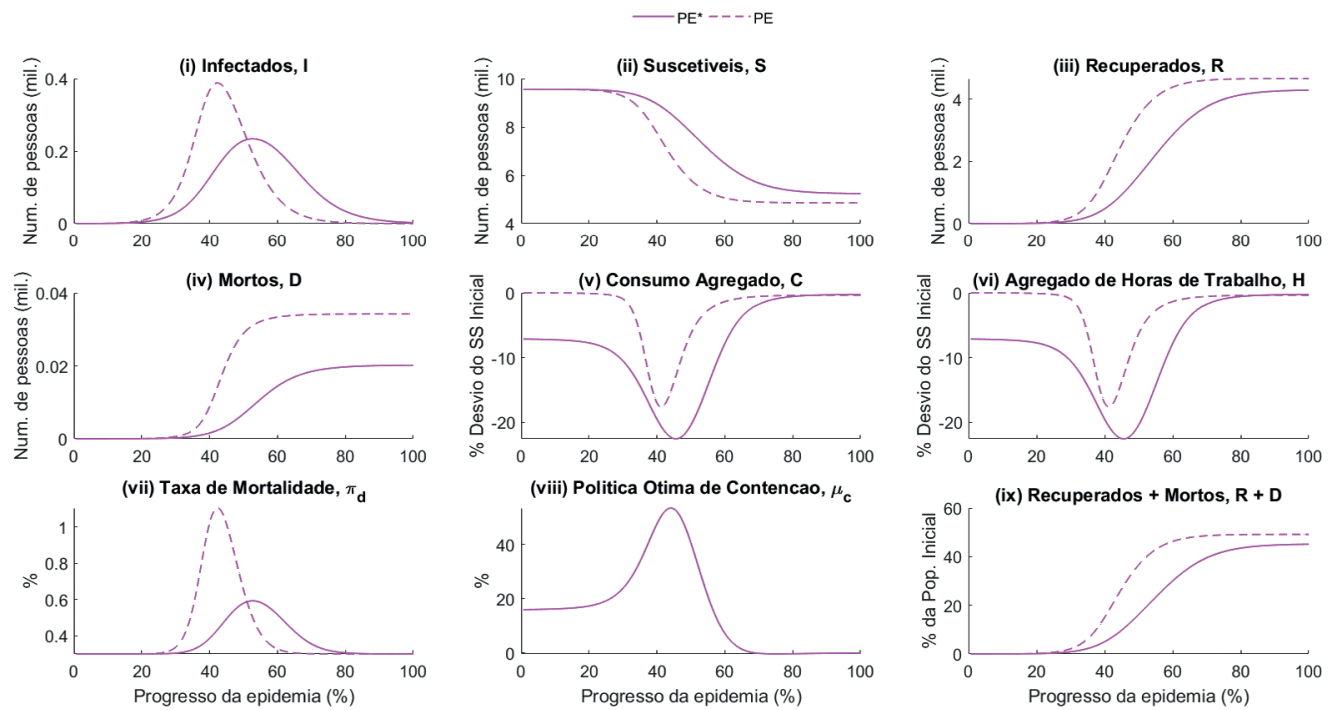

Elaboração dos autores

Obs.: Figura cujos leiaute e textos não puderam ser padronizados e revisados em virtude das condições técnicas dos originais (nota do Editorial). Notas: ${ }^{1}$ Linha sólida.

${ }^{2}$ Linhas pontilhadas.

\section{CONCLUSÃO}

Na seção 2 apresentamos o modelo SIR-macro completo, conforme desenvolvido por Eichenbaum (2020). Na seção 3 expomos nossa estratégia de calibragem para cada um dos estados. Essa estratégia de calibragem foi a responsável por captar diferenças de cada estado relativas: $i$ ) ao tamanho da populaçáo; ii) à renda per capita; iii) ao tempo médio dedicado ao trabalho; $i v$ ) ao tempo médio no transporte; $v$ ) ao tempo médio dedicado a afazeres domésticos; vi) à quantidade média de pessoas por residência; vii) à quantidade de pessoas ocupadas na força de trabalho; viii) à quantidade de estudantes; e $i x$ ) às diferenças nas taxas de fatalidade estimadas com a evolução da epidemia até o momento da pesquisa. Na seçáo 4 apresentamos resultados para os cinco estados sob o cenário de equilíbrio competitivo, isto é, na ausência da adoçáo de medidas de contenção por parte das autoridades de cada estado. Na seçáo 5 apresentamos as medidas de contenção ótimas que poderiam ser adotadas por cada um dos estados. Finalmente, na seçáo 6 apresentamos os resultados no cenário em que cada um dos estados adota as medidas de contenção expostas na seção 5 e comparamos as consequências destas medidas em relação ao cenário de equilíbrio competitivo apresentado na seção 4 . 
Nosso interesse foi analisar qualitativamente como as principais diferenças intrínsecas a cada estado podem afetar as suas dinâmicas epidêmicas e seus resultados. Em particular, nossos exercícios, efetuados para cinco estados (São Paulo, Amazonas, Ceará, Rio de Janeiro e Pernambuco) e selecionados pela severidade da epidemia que apresentavam no momento da pesquisa, apontaram para diferenças substanciais na evolução e no resultado da epidemia em cada um, tanto no cenário de equilíbrio competitivo quanto no cenário em que políticas ótimas de contenção são adotadas. Em ambos os cenários, não apenas o tamanho do pico de infectados e o tempo necessário para alcança-lo diferiram em cada estado; também diferiram a profundidade e a duração das recessōes, juntas à parcela da população total infectada e à parcela da população inicial acometida pela morte ao fim da epidemia em cada estado.

Nossos resultados apresentam evidências de que as diferenças intrínsecas de cada estado implicam também trajetórias ótimas de políticas de contenção diferentes para cada um deles. Essas diferenças intrínsecas não apenas afetam a severidade inicial das medidas de contenção adotadas por cada estado como também a dinâmica da evolução destas taxas de contenção no tempo. Isso implica diferenças no momento ideal em que as medidas de contenção precisarão ser elevadas, até onde elas precisarão ser elevadas e quando poderão ser finalmente relaxadas. Tendo em vista que em alguns estados são necessárias medidas mais severas e/ou prolongadas de contenção, enquanto em outros, medidas menos severas e/ou abreviadas, nosso estudo aponta que haverá uma consequência desta heterogeneidade nas tragetótias ótimas; pois, com a adoção destas políticas de contenção, são evidenciadas as alteraçóes - observadas no equilíbrio competitivo nas relações de ordem de grandeza e temporais entre os estados.

Usando o arcabouço simples do modelo SIR-macro proposto por Eichenbaum $e t$ al. (2020) e analisando os resultados obtidos para cada estado concluímos, em primeiro lugar, que o equilíbrio competitivo não é socialmente ótimo para nenhum dos estados, sendo, portanto, a adoção de políticas de contenção por parte dos estados as melhores respostas à eclosão da epidemia. Em segundo lugar, que as características implícitas dos cinco diferentes estados implicam diferenças relevantes aos seguintes aspectos:

- na dinâmica epidêmica e suas consequências epidemiológicas gerais;

- nas políticas ótimas de contenção a serem adotadas por cada estado;

- no efeito da adoção das políticas ótimas de contenção; e

- na severidade das recessóes econômicas resultantes da epidemia. 
Esta conclusão corrobora com ênfase que vem sido dada na literatura nacional à importância da análise desagregada do país para a formulação de políticas de combate à pandemia. A adoção de uma política única para um país das dimensôes do Brasil pode provocar reaçóes desproporcionais nas esferas estaduais. Com efeito, se a política do país for acima da requerida para determinados estados, estes podem sofrer agravos desnecessários de suas recessóes econômicas. Num pior cenário, por outro lado, se a política adotada por todo o país for abaixo da requerida por determinados estados, a consequência pode ser a elevaçáo do número de mortos resultante da pandemia nestes estados. Portanto, em última análise, o enfrentamento desagregado da pandemia pode colaborar tanto para a menor severidade da recessão econômica sofrida pelo país como um todo, quanto para a preservação de um maior número de vidas.

\section{REFERÊNCIAS}

EICHENBAUM, M. S., REBELO, S. e TRABANDT, M. The Macroeconomics of Epidemics, Tech. rep, National Bureau of Economic Research. 2020.

FARHI, E. e WERNING, I. "Dealing with the Trilemma: Optimal Capital Controls with Fixed Exchange Rates", National Bureau of Economic Research Working Paper No. 18199. 2012.

FERRARI, T. K., DUSI, L. D. A., LOPES, D. A. F. e POMPERMAYER, M. "Estimativa do valor da vida estatística e do valor da economia de tempo em viagens nas rodovias brasileiras com a utilização de pesquisa de preferência declarada”. 2019.

HALLAL, P. et al. "Remarkable variability in Sars-COV-2 antibodies across Brazilian regions: nationwide serological household survey in 27 states", medRxiv doi: 10.1101/2020.05.30.20117531. 2020.

KERMACK, W. e MCKENDRICK, A. "A Contribution to the Mathematical Theory of Epidemics", Proceedings of the Royal Society of London, series A 115, no. 772: 700-721, 1927. 1927.

FERGUSON, N. M., CUMMINGS, D. A., FRASER, C., CAJKA, J. C., COOLEY, P. C. e BURKE, D. S. "Strategies for mitigating an influenza epidemic", Nature, 442, 448-452. 2006.

LEE, B. Y., BROWN, S. T., COOLEY, P. C., ZIMMERMAN, R. K., WHEATON, W. D., ZIMMER, S. M., GREFENSTETTE, J. J., ASSI, T.-M., FURPHY, T. J. e WAGENER, D. K. "A computer simulation of employee vaccination to mitigate an influenza epidemic", American Journal of preventive medicine, 38, 247-257. 2010. 
MELLAN, T. A. et al. "Report 21: Estimating Covid-19 cases and reproduction number in Brazil”, Imperial College Covid-19 Response Team. 2020.

RABELO, M. e SOARES, J. “The Macroeconomics of Epidemics: results for Brazil”. Working paper. 2020.

ROCHA, G., DE MORAIS, R. L. e KLUG, L. "O custo econômico da poluição do ar: Estimativa de valor da vida estatística para o Brasil”, Tech. Rep., Texto para Discussão. 


\section{APÊNDICE A}

\section{CALIBRAGEM DE $\alpha_{1}, \alpha_{2}$ E $\alpha_{3}$}

Calibramos as parcelas das transmissóes que ocorrem no consumo, no trabalho e em outras atividades como proporcionais ao tempo que os indivíduos passam executando estas atividades. Para calibrar $\alpha_{1}$, Eichenbaum et al. (2020) utiliza dados de pesquisas de uso de tempo produzidas pelo Bureau of Labor Statistics, dos Estados Unidos. Diante da inexistência de pesquisas equivalentes para o Brasil, calibrar diretamente a parcela das transmissóes que ocorrem no consumo tornou-se tarefa deveras complicada para os estados brasileiros. Entáo, decidimos calibrar os valores de $\alpha_{2}$ e $\alpha_{3}$ e obter os valores de $\alpha_{1}$ residualmente. Calibramos a parcela das transmissóes que ocorrem no trabalho, $\alpha_{2}$, utilizando a mesma abordagem de Eichenbaum et al. (2020). Ponderamos a quantidade de estudantes e trabalhadores de cada estado em 10 e 4, respectivamente. Estes pesos dizem respeito à quantidade média de contatos físicos por dia na escola e no trabalho, obtidas no estudo de Lee et al. (2010). Desagregamos a fração das transmissóes que ocorre em escolas e ambientes de trabalho para obter a fração que ocorre apenas nos ambientes de trabalho considerando, para isso, uma proporcionalidade envolvendo a quantidade média de contatos, a população de trabalhadores e a população de estudantes de cada estado. Calculamos a proporção das infecçốes que ocorre apenas no trabalho e, finalmente, obtemos o valor de $\alpha_{2}$ multiplicando-a pela parcela das infecçóes que ocorre em escolas e ambientes de trabalho (37\%). Assim, para cada estado o valor de $\alpha_{2}$ será calculado como sendo:

$$
\alpha_{2}=\frac{4 \cdot(\text { Trabalhadores })}{4 \cdot(\text { Trabalhadores })+10 \cdot(\text { Estudantes })} \cdot 37 \%
$$

onde Trabalhadores é a quantidade total de trabalhadores do estado em questão e Estudantes é a quantidade total de estudantes do estado em questáo. Para a quantidade total de trabalhadores utilizou-se o número de pessoas de 14 anos ou mais de idade, na força de trabalho, ocupadas, por unidade da federaçáo, obtidos no Sistema IBGE de Recuperação Automática (SIDRA), ${ }^{1}$ do Instituto Brasileiro de Geografia e Estatística (IBGE). Para a quantidade total de estudantes utilizou-se o número de estudantes de 4 anos ou mais de idade, por unidade de federação, obtidos também no SIDRA, ${ }^{2}$ do IBGE.

1. Tabela 4093.

2. Tabela 983. 
Agora procedemos a calibragem da parcela das infecçóes que ocorre em outras atividades, $\alpha_{3}$. Essa parcela é, por definição, a parcela das infecçôes que ocorre em todas as atividades exceto consumo e trabalho. Evidentemente, são muitas estas atividades, de modo que se torna inevitável a necessidade de hipóteses simplificadora para o seu cálculo.

Abordamos esse problema da seguinte forma: assumimos como hipótese de calibragem que a grande maioria das infecçôes que ocorrem fora do consumo e do trabalho ocorrem, principalmente, em casa, na escola ou no transporte. Esta hipótese é definida de acordo com a nossa intuição a respeito da natureza da transmissáo do vírus inserida na realidade brasileira e com a disponibilidade de dados para os estados. Sabemos que esta hipótese deixa de lado uma série de outras circunstâncias e ambientes em que a transmissão da doença poderia ocorrer, talvez o mais significativo deles sendo os próprios hospitais. Não obstante, a ausência de dados estaduais específicos relacionados a estas condiçôes e ambientes não nos permitem mensurar com precisão estas parcelas.

Contornamos esse problema da seguinte maneira: se calibrarmos $\alpha_{3}$ em função apenas do tempo que as pessoas passam em casa, no transporte e na escola, o valor resultante apresenta-se deveras baixo e, como consequência, calculando residualmente a parcela $\alpha_{1}$ relativa às infecçóes que ocorrem no consumo, observamos que esta parcela apresenta-se, por outro lado, irrealisticamente alta. Isto ocorre por dois principais fatores. Em primeiro lugar, pela questáo já anteriormente citada (nossa hipótese de calibragem para $\alpha_{3}$ deixa de fora muitos ambientes de alto grau de infecção, como hospitais, fazendo com que o valor resultante para esta parcela seja subestimado) e, em segundo lugar, pois a parcela das infecçóes não deve ser explicada apenas pelo tempo despendido em cada ambiente, mas sim por esse tempo propulsionado por um fator multiplicador relacionado às características do ambiente em questão. Todas essas constatações indicam que o valor de $\alpha_{3}$, se calculado desta forma, é subestimado, o que nos dá margem para acresce-lo por meios alternativos para incorporar o efeito destes fatores omitidos.

Optamos por incorporar a contribuição dos ambientes omitidos para as infecçóes no fator multiplicador do transporte. Mas o quão grande deve ser este fator multiplicador? Nós o calibramos de modo a obter valores para as parcelas $\alpha_{3}$ dos estados que girem em torno de um a dois terços, magnitudes consistentes com o valor obtido por Eichenbaum et al. (2020) para os Estados Unidos, onde a disponibilidade de dados possibilitou o cálculo residual de $\alpha_{3}$ contribuindo, portanto, para a maior 
confiabilidade da estimativa de grandeza desta parcela. Como este fator multiplicador será comum para todos os estados, argumentamos não haver perda qualitativa para o modelo, uma vez que as diferenças relativas de calibragem entre estados não serão alteradas.

Para calibrar $\alpha_{3}$ procedemos, então, da seguinte forma: calculamos a fração das infecções que ocorre em casa, $\alpha_{3}{ }^{C A S A}$, nas escolas, $\alpha_{3}{ }^{E S C O L A S}$ e no transporte, $\alpha_{3}{ }^{T R A N S P}$, e somamos, de modo que $\alpha_{3}=\alpha_{3}{ }^{\text {CASA }}+\alpha_{3}{ }^{\text {ESCOLAS }}+\alpha_{3}{ }^{\text {TRANSP }}$. Ora, note que com o cálculo da parcela das infecçôes que ocorre nos ambientes de trabalho, $\alpha_{2}$, obtém-se, consequentemente, também a parcela das infecçóes que ocorre nas escolas:

$$
\alpha_{3}{ }^{\text {ESCOLAS }}=37 \% \cdot \frac{10 \cdot(\text { Estudantes })}{4 \cdot(\text { Trabalhadores })+10 \cdot(\text { Estudantes })} .
$$

O problema de calibragem de $\alpha_{3}$ reduz-se, portanto, a calibrar as fraçóes de infecçóes que ocorrem em casa, $\alpha_{3}{ }^{C A S A}$, e no transporte, $\alpha_{3}{ }^{\text {TRANSP. }}$.

Para calibrar a fração das infecçóes que ocorre em casa utilizamos dados sobre a proporção de horas diárias dedicadas aos cuidados de pessoas e/ou afazeres domésticos, das pessoas de 14 anos ou mais de idade (\%), por unidade da federação, obtidos no SIDRA ${ }^{3}$ do IBGE, para calcular a proporção média do tempo diário que os indivíduos de cada estado passam em casa em situaçôes suscetíveis à infecção. Como o tempo de sono não pode ser considerado tempo suscetível à infecção, consideramos um tempo médio de sono de 8 horas diárias e calculamos a proporçáo como sendo as horas diárias dedicadas aos cuidados de pessoas e/ou afazeres domésticos de cada estado divididas por 16 (24-8). Recorde-se, do trabalho de Ferguson et al. (2006), que $30 \%$ das infecçôes ocorrem em casa. Então multiplicamos essa proporção por $30 \% \mathrm{e}$ ainda, sob a hipótese de que quanto mais pessoas por domicílio, maior a parcela de infecçôes dentro de casa, por um fator multiplicador caracterizado pelo número médio de pessoas por domicílio, em 2019, obtidos no SIDRA ${ }^{4}$ do IBGE para cada estado. $\mathrm{O}$ valor resultante de $\alpha_{3}{ }^{C A S A}$ para cada estado é descrito, portanto, pela equação 


$$
\alpha_{3}{ }^{C A S A}=30 \% \cdot \frac{(\text { Afazeres domésticos })}{16} \cdot(\text { Pessoas por residência })
$$

onde Afazeres domésticos é o tempo médio diário que os indivíduos do estado em questáo dispendem com afazeres domésticos e Pessoas por residência é o número médio de pessoas vivendo por residência no estado em questão.

Finalmente, para calibrar a fração que ocorre no transporte, $\alpha_{3}{ }^{\text {TRANSP }}$, procedemos utilizando o tempo habitual de deslocamento para o trabalho dos indivíduos, obtidos no SIDRA 5 do IBGE para cada estado, para calcular a fraçáo do tempo das atividades gerais destinada ao uso de transporte. Consideramos o tempo das atividades gerais como sendo as 24 horas diárias subtraídas do tempo gasto em afazeres domésticos, sono, trabalho e escola. Tendo obtida a fração do tempo devotada às atividades gerais que é destinada ao uso de transporte, nós a multiplicamos pela parcela das infecçôes que ocorrem em atividades gerais (33\%) para obter a parcela das infecçôes que ocorrem no transporte. Finalmente, calibramos o fator multiplicador do transporte de modo que os valores de $\alpha_{3}$ girem em torno de um a dois terços para todos os estados, intervalo de valores consistente com os valores de $\alpha_{3}$ calibrados em Eichenbaum et al. (2020) para os Estados Unidos, onde a disponibilidade de dados para a calibragem é mais ampla. $\mathrm{O}$ fator multiplicador é, portanto, definido como sendo 10 . O valor de $\alpha_{3}{ }^{T R A N S P}$ é, entâo, obtido para cada estado pelo cálculo

$$
\alpha_{3}{ }^{\text {TRANSP }}=33 \% \cdot \frac{(\text { Tempo médio no transporte })}{16-(\text { Afazeres domésticos })-(\text { Trab.ou escola })} \cdot 10 .
$$

Com isso, finalmente o valor de $\alpha_{3}$ é obtido como sendo

$$
\alpha_{3}=\alpha_{3}{ }^{C A S A}+\alpha_{3}{ }^{\text {ESCOLAS }}+\alpha_{3}^{\text {TRANSPORTE }} .
$$

Tendo obtidas as parcelas $\alpha_{1}, \alpha_{2}$ e $\alpha_{3}$, bastará resolver o sistema (31) para obter os valores de $\pi_{1}, \pi_{2}$ e $\pi_{3}$. 


\section{ANEXO A}

\section{COMPUTANDO 0 EQUILÍBRIO}

Neste apêndice é transcrito o método de computação do equilíbrio do modelo conforme exposto em Eichenbaum et al. (2020). In verbis:

Para uma dada sequência de taxas de contenção $\left\{\mu_{t}\right\}_{t=0}^{H-1}$ e para algum horizonte suficientemente grande $H$, arbitre sequências para $\left\{n_{t}^{s}, n_{t}^{i}, n_{t}^{r}\right\}_{t=0}^{H-1}$ Na prática, resolvemos o modelo para $H=250$. Compute a sequência das variáveis desconhecidas remanescentes em cada uma das seguintes equações de equilíbrio:

$$
\begin{gathered}
\theta n_{t}^{r}=A \lambda_{b t}^{r}, \\
\left(c_{t}^{r}\right)^{-1}=\left(1+\mu_{t}\right) \lambda_{b t}^{r}, \\
u_{t}^{r}=\ln c_{t}^{r}-\frac{\theta}{2}\left(n_{t}^{r}\right)^{2} .
\end{gathered}
$$

Itere retroativamente partindo dos valores de $U_{t}^{r}$ do estado estacionário pós-epidêmico:

$$
U_{t}^{r}=u\left(c_{t}^{r}, n_{t}^{r}\right)+\beta U_{t+1}^{r} .
$$

Calcule a sequência de incógnitas remanescentes nas seguintes equações:

$$
\begin{gathered}
\left(1+\mu_{t}\right) c_{t}^{r}=A n_{t}^{r}+\Gamma_{t} \quad\left(\lambda_{b t}^{r}\right), \\
\theta n_{t}^{i}=\phi^{i} A \lambda_{b t}^{i}, \\
\left(c_{t}^{i}\right)^{-1}=\lambda_{b t}^{i}, \\
u_{t}^{i}=\ln c_{t}^{i}-\frac{\theta}{2}\left(n_{t}^{i}\right)^{2}, \\
\left(1+\mu_{t}\right) c_{t}^{s}=A n_{t}^{s}+\Gamma_{t} \quad\left(\lambda_{b t}^{s}\right), \\
u_{t}^{s}=\ln c_{t}^{s}-\frac{\theta}{2}\left(n_{t}^{s}\right)^{2} .
\end{gathered}
$$


Dados os valores iniciais de $P o p_{0}, S_{0}, I_{0}, R_{0}$ e $D_{0}$, itere para frente usando as seguintes equaçóes para $t=0, \ldots, H-1$ :

$$
\begin{gathered}
T_{t}=\pi_{1}\left(S_{t} c_{t}^{S}\right)\left(I_{t} c_{t}^{i}\right)+\pi_{2}\left(S_{t} n_{t}^{S}\right)\left(I_{t} n_{t}^{i}\right)+\pi_{3} S_{t} I_{t}, \\
\operatorname{Pop}_{t+1}=P_{t}-\pi_{d} I_{t}, \\
S_{t+1}=S_{t}-T_{t} \\
I_{t+1}=I_{t}+T_{t}-\left(\pi_{r}+\pi_{d}\right) I_{t} \\
R_{t+1}=R_{t}+\pi_{r} I_{t} \\
D_{t+1}=D_{t}+\pi_{d} I_{t} .
\end{gathered}
$$

Itere retroativamente partindo dos valores de $U_{t}^{S}$ e $U_{t}^{i}$ do estado estacionário pós-epidêmico:

$$
\begin{gathered}
U_{t}^{i}=u\left(c_{t}^{i}, n_{t}^{i}\right)+\beta\left[\left(1-\pi_{r}-\pi_{d}\right) U_{t+1}^{i}+\pi_{r} U_{t+1}^{r}\right], \\
\tau_{t}=\frac{T_{t}}{S_{t}} \\
U_{t}^{S}=u\left(c_{t}^{S}, n_{t}^{S}\right)+\beta\left[\left(1-\tau_{t}\right) U_{t+1}^{S}+\tau_{t} U_{t+1}^{i}\right] .
\end{gathered}
$$

Calcule a sequência das incógnitas remanescentes nas seguintes equações:

$$
\begin{gathered}
\beta\left(U_{t+1}^{i}-U_{t+1}^{S}\right)-\lambda_{\tau t}=0, \\
\left(c_{t}^{S}\right)^{-1}-\lambda_{b t}^{s}\left(1+\mu_{t}\right)+\lambda_{\tau t} \pi_{1}\left(I_{t} C_{t}^{I}\right)=0 .
\end{gathered}
$$

Finalmente, use um método baseado em gradientes para ajustar os valores arbitrados $\left\{n_{t}^{s}, n_{t}^{i}, n_{t}^{r}\right\}_{t=0}^{H-1}$ de modo que as seguintes três equações valham com precisão arbitrária:

$$
\begin{gathered}
\left(1+\mu_{t}\right) c_{t}^{i}=\phi^{i} A n_{t}^{i}+\Gamma_{t} \quad\left(\lambda_{b t}^{i}\right), \\
\mu_{t}\left(S_{t} c_{t}^{s}+I_{t} c_{t}^{i}+R_{t} c_{t}^{r}\right)=\Gamma_{t}\left(S_{t}+I_{t}+R_{t}\right), \\
-\theta n_{t}^{s}+A \lambda_{b t}^{s}+\lambda_{\tau t} \pi_{2}\left(I_{t} n_{t}^{I}\right)=0
\end{gathered} .
$$


Ipea - Instituto de Pesquisa Econômica Aplicada

\section{EDITORIAL}

\section{Coordenação}

Reginaldo da Silva Domingos

Assistente de Coordenação

Rafael Augusto Ferreira Cardoso

\section{Supervisão}

Camilla de Miranda Mariath Gomes

Everson da Silva Moura

\section{Editoração}

Aeromilson Trajano de Mesquita

Cristiano Ferreira de Araújo

Danilo Leite de Macedo Tavares

Herllyson da Silva Souza

Jeovah Herculano Szervinsk Junior

Leonardo Hideki Higa

\section{Capa}

Danielle de Oliveira Ayres

Flaviane Dias de Sant'ana

\section{Projeto Gráfico}

Renato Rodrigues Bueno

The manuscripts in languages other than Portuguese published herein have not been proofread.

\section{Livraria Ipea}

SBS - Quadra 1 - Bloco J - Ed. BNDES, Térreo

70076-900 - Brasília - DF

Tel.: (61) 2026-5336

Correio eletrônico: livraria@ipea.gov.br 

Composto em adobe garamond pro 12/16 (texto) Frutiger 67 bold condensed (títulos, gráficos e tabelas) Brasilia-DF 



\section{Missão do Ipea}

Aprimorar as políticas públicas essenciais ao desenvolvimento brasileiro por meio da produção e disseminação de conhecimentos e da assessoria ao Estado nas suas decisões estratégicas.

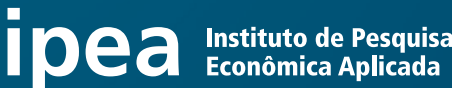 \\ MINISTÉRIO DA \\ ECONOMIA

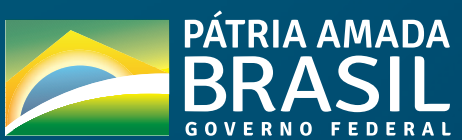

